\title{
CLUNIO boudouresQueI SP. N. AND THALASSOSMITTIA BALLESTAI SP. N., TWO Tyrrhenian marine SPecies occurring in Scandola Nature Reserve, West Corsica (Diptera: Chironomidae)
}

\author{
Joel Moubayed-Breil ${ }^{1} \&$ Jean-Marie Dominici² \\ ${ }^{1}$ Freshwater \& Marine biology, 10 rue des Fenouils, F-34070 Montpellier, France. \\ E-mail: mvp5133@gmail.com, corresponding author \\ ${ }^{2}$ Nature Reserve of Scandola (Regional Nature Park of Corsica), 20245 Galéria, Corsica, France. \\ E-mail: pnrc.scandola-jm@wanadoo.fr
}

http://zoobank.org/4E98B6AF-1BFF-4C12-BCF0-C416B600CA94

\begin{abstract}
Clunio boudouresquei sp. n. and Thalassosmittia ballestai sp. n. are diagnosed and described based on associated material of male adults, pharate male adults and pupal exuviae recently collected in the marine littoral zone of Scandola Nature Reserve (Cala Litizia, Punta Palazzu, Focolara Bay, West Corsica). While C. boudouresquei sp. $\mathrm{n}$. is described as male and female adults and pupal exuviae, T. ballestai sp. $\mathrm{n}$. is described only as male adult and pupal exuviae. On the basis of some atypical characters found in the male adult and pupal exuviae, both C. boudouresquei sp. n. and T. ballestai sp. n. appear to belong, to a local Tyrrhenian element. Biological cycles of both new species are closely related to alternation between marine and terrestrial ecological conditions, which are strongly reinforced during spring tides of lunar rhythms. Larval stages of both new species are typically marine shore dwellers of the intertidal zone along seacoasts of the Tyrrhenian sub-region, where the biological and ecological quality of marine coastal habitats are being seriously damaged by various anthropogenic activities. In the latter sites, the Lithophyllum byssoides (Lamarck) Foslie pavements (trottoirs, encorbellements) are actually threatened by the massive proliferation of Sea Mussels (Mytilidae), which predominate when changes in water quality and level of pollution become increasingly high. The two new species are considered as pertinent biological indicators of the marine coastal habitats around the Tyrrhenian Region, in particular, those delimited by the mid-littoral large bio-constructions of the red calcified alga L. byssoides, where the larvae of C. boudouresquei sp. n. are exclusively confined. Such threatened species are considered biogeographic Tyrrhenian representatives and indicators of global warming and local climate change in the region, particularly to a rising sea level. Comments
\end{abstract}

on the taxonomic position, ecology and geographical distribution of the new species are given.

\section{Introduction}

Recent investigations of marine chironomids conducted in the protected area of Scandola Nature Reserve (West Corsica), allowed us to sample fully developed pharate, adults, pupae and pupal exuviae of two new species, which belong to the genera Clunio Haliday, 1855 and Thalassosmittia Strenzke \& Remmert, 1957. The two new species (C. boudouresquei sp. n. and T. ballestai sp. n.) were previously reported by Moubayed-Breil et al. (2013) and Moubayed-Breil \& Ashe (2012) as, Clunio sp. 1 and Thalassosmittia sp. 1. Worldwide the genus Clunio is known from all geographic regions, while Thalassosmittia is restricted the Neotropical, Nearctic, Palaearctic and Afrotropical regions.

Data on the taxonomy and geographical distribution of known valid species of these two genera from Europe and some neighbouring areas show that there are about 25 species for the genus Thalassosmittia and about 10 species for the genus $\mathrm{Cl}$ unio (Saunders 1928; Storå 1936; Tokunaga 1936; Strenzke \& Remmert 1957; Strenzke 1960; Sæther 1969; Morley \& Ring 1972; Neumann 1976; Sæther 1977; Heimbach 1978; Michailova 1980a, 1980b; Coffman et al. 1986; Cranston et al. 1989; Langton 1991; Wang \& Sæther 1993; Neumann et al. 1997; Sasa \& Suzuki 1999a, 1999b; Yamamoto 2004; Langton \& Pinder 2007; Tasdemir 2010; Sæther \& Andersen 2011; Ashe \& O’Connor 2012; Kaiser \& Heckel 2012; Sæther \& Spies 2013; Andersen \& Pinho 2014; Moubayed-Breil \& Ashe 2012; Andersen et al. 2013; Moubayed-Breil et al. 2013; Moubayed-Breil \& Ashe 2016; Yamamoto et al. 2019). Consequently, the description of $C$. boudouresquei sp. n. and T. ballestai sp. n. increases worldwide the total number of described species to 26 for the genus Thalassosmittia and to 
11 for the genus Clunio.

In this paper, C. boudouresquei sp. n. and T. ballestai sp. n. are described and diagnosed based on associated material recently collected in the marine littoral zone of Scandola Nature Reserve (Focolara Bay) located in western Corsica. While C. boudouresquei sp. n. is described as male and female adults and pupal exuviae, T. ballestai sp. n. is described only as male adult and pupal exuviae. On the basis of some atypical characters found in the male adult (shape of head, palpomeres, apodemes, tergite IX, inferior volsella, gonostylus) and pupal exuviae (distribution pattern of armament on tergites and sternites), C. boudouresquei sp. n. and T. ballestai sp. n. appear to belong, each to a local Tyrrhenian marine element.

Larval stages of both new species are typically marine shore dwellers of the intertidal zone along seacoasts, where dense populations are often reported. In particular, those of $C$. boudouresquei sp. n. are exclusively confined to the intertidal habitats delimited by the mid-littoral large bio-constructions (pavements, 'trottoirs') of the 'long-living' red calcified alga Lithophyllum byssoides (Lamarck) Foslie, which are locally present in both western Corsica (Punta Palazzu) and southern France. In addition, the latter pristine habitats are considered to be microrefugia for a well-diversified biocoenosis including marine and semi-terrestrial taxa/species. The two new species are considered as pertinent indicators of the environmental quality of seacoasts around the Tyrrhenian Region (insular and continental Provinces), where changes in biological and ecological conditions of the intertidal zone are presumably being the result of human activities and global warming in this region.

\section{Material and methods}

Material composed of adults, pharate adults and pupal exuviae belonging to both $C$. boudouresquei sp. n. and T. ballestai sp. n. was collected using standard methods: troubleau net for the benthos (larvae and pupae) and individuals floating on the surface of the water; Brundin drift nets towed behind a boat for pharates, pupae and drifted pupal exuviae; sweep net for flying adults. Additional inorganic material composed of plastics (micro- + macroplastics) and pellet tar (0.5-5 to $10-15 \mathrm{~mm})$, was also collected during the fieldwork, which were especially of great interest for useful comments on both biological and ecological quality of environment. Male adults were preserved in $80-85 \%$ ethanol, then cleared of musculature in 90\% lactic acid (head, thorax, abdomen and anal segment) for 60 to 80 minutes; this can be left overnight at room temperature without any detrimental effect or damage. The specimens were checked under a binocular microscope after 20 minutes in lactic acid to determine how the clearing was progressing. When clearing was complete the specimens were washed in two changes of $70 \%$ ethanol to ensure that all traces of lactic acid were removed.

The studied material was mounted in polyvinyl lactophenol. Before the final slide mountings of the type and paratype material in dorsal view, the hypopygium including tergite IX and anal point, the gonocoxite and the gonostylus, were viewed ventrally and laterally to examine and draw from both sides all the necessary details of the species. In particular, the ventral view of hypopygium was illustrated when the anal point and tergite IX were removed. For a better examination of the specific features and more accurate description of the various taxonomic details of the pupa, the pupal abdomen was mounted not only in dorsal and ventral view, but separately in lateral view, which facilitates proper examination and illustration of all the relevant taxonomic characters. The proximal part of the abdomen and the halteres of the male adult were preserved in $85 \%$ ethanol for an eventual DNA analysis. Morphological terminology and measurements follow those of Sæther (1980), Langton (1991) and Langton \& Pinder (2007) for the imagines and pupal exuviae. Taxonomic remarks on some related known species from Europe with comments on the ecology and geographical distribution of the two new species are given.

\section{Description}

Clunio boudouresquei Moubayed-Breil, sp. n.

Clunio sp. 1, in Moubayed-Breil \& Ashe (2012), Moubayed-Breil et al. (2013).

http://zoobank.org/3B0274A6-5460-4D84-80282BF8903468B9

\section{Material examined}

Holotype. France, West Corsica, Scandola Nature Reserve, Focolara Bay, Cala Litizia, bioconstructions of the red calcified marine alga L. byssoides of Punta Palazzu locality (Fig. 10), $42^{\circ} 21^{\prime} 25^{\prime \prime} \mathrm{N}, 8^{\circ} 34^{\prime} 0^{\prime \prime} \mathrm{E}$; 1 male pharate adult, leg. J. Moubayed-Breil, 03.VI.2015. Locality No. 31 in Moubayed-Breil \& Ashe (2012); locality No. 30 in Moubayed-Breil et al. (2013). Marine water temperature: $10-12^{\circ} \mathrm{C}$ (min.), $22-24^{\circ} \mathrm{C}$ (max.).

Paratypes (all leg J.M-B.): 2 male adults, 1 female adult, 6 pupal exuviae (4 males and 2 females), same locality as for holotype, 03.VI.2015. 
Holotype (mounted on 1 slide) and 2 pupal exuviae ( 1 male and 1 female) are deposited in the collections of the Zoologische Staatssammlung München (ZSM), Munich, Germany. Additional paratypes are deposited in the senior author's collection.

\section{Diagnostic characters}

Based on some characters found in the male adult (vertex with lateral projections, typical morphology of inferior volsella and both basal and caudal apodemes, presence of megaseta on gonostylus), C. boudouresquei sp. n. appears to belong to a local Tyrrhenian marine element. However, this new species can be distinguished from other European Clunio species by the blow listed characters.

Male adult: Vertex with two lateral triangular projections; antenna 10-segmented, last flagellomere longer than the 3 preceding segments; sensilla chaetica present on tibia and ta1 of PI-PIII; tergite VIII with a distinct elongate ellipse-like ridge located antero-medially, midline area with 6 short setae; apical expansion of tergite IX distinctly convex at apex; caudal apodeme with 5-6 curved claw-like tubercles; inferior volsella wider at base and narrowing distally; gonostylus unusually bearing a black fingernail-like megaseta, apex ending with a single finger-like tubercle.

Female adult: Eyes densely haired, temporals 2 including 1 inner and 1 outer vertical; clypeus semi-circular, bare; antenna 7-segmented, last flagellomere elongated, segments 6 and 7 each with 1 tubular sensilla chaetica; palpomere 2, globular, with 3 sensilla clavata distally and 1 long fine seta; tarsomere ta $\mathrm{t}_{1}$ of PI and PII is half long as ta $\mathrm{ta}_{1}$ of PIII; sensilla chaetica present on tibia and tarsomere ta of PI, PII and PIII; sternite VIII with 22-24 setae; dorsomesal lobe of gonapophysis VIII convex medially and projecting; apodeme lobe swollen in its postero-median part; 2 stout inwardly directed setae present on each side of gonapophysis VIII; seminal capsules sub-oval; tergite IX oval, markedly divided, with 20-22 setae; gonocoxite weekly developed; cercus sub-rectangular.

Pupal exuviae: Antero-median area of frontal apotome and thorax with wrinkles; frontal setae present on distal part of frontal apotome; dorsocentrals $\mathrm{Dc}_{1}-\mathrm{Dc}_{2}$ and $\mathrm{Dc}_{3}-\mathrm{Dc}_{4}$ located close together; anterior transverse rows of spines interrupted on tergite II; posterior transverse rows of hooks present on sternites V-VII.

Etymology: the new species is named 'boudouresquei' in honour of our colleague Ch-Fr. Boudouresque (University of Sciences, Luminy, Mar- seille), who is still active in studying the biology and ecology of the Mediterranean marine flora and fauna including those of the protected area of Scandola Nature Reserve. As he always did in past, he keeps working on developing projects to preserve the marine protected area of Scandola Nature Reserve, which represents a precious and valuable inheritance area.

\section{Male adult}

$(\mathrm{n}=5,2$ pharates; Figs 1c-h, 2a-d, 3a-b)

Total length 2.70-2.90 mm. Wing length 1.35-1.40 $\mathrm{mm}, \mathrm{TL} / \mathrm{WL}=2-2.10$. General colouration contrasting brown to dark brown. Head and antennae dark brown; thorax contrasting light brown to brown with dark brown mesonotal stripes; wing pale translucent; legs brown to dark brown; tergites I-VII brownish, tergite VIII and anal distinctly contrasting light brown to dark brown.

Head. Eyes sub-circular without dorso-median extension, densely hairy with long and short pinlike hairs; hairs absent on inner lateral eye margin, outer posterior margin lacking setae. Vertex (Fig. 1c, dorsal; Fig. 1d, ventral) with 2 triangular lateral expansions; temporals 2 consist only of 2 outer verticals, postorbitals absent. Antenna 10-segmented, about $500 \mu \mathrm{m}$ long, lacking plume; segment 1-2 (Fig. 1e), segment 1 globular, segment $2145 \mu \mathrm{m}$ long, linearly elongated; segment 2-9 globular, nearly sub-equal (30-40 $\mu \mathrm{m}$ long); ultimate flagellomere (Fig. 1f) $105 \mu \mathrm{m}$ long, about $40 \mu \mathrm{m}$ maximum width, as longer than the 3 preceding segments, thumb-like shaped; sensilla chaetica present on segments 1 to 8 ; antennal groove reaching segment 2; AR 0.27. Palp (Figs 1g-h) 2-segmented, lacking sensilla clavata; left palpomeres 1-2 respectively 25 and $55 \mu \mathrm{m}$ long, palpomere 2 ending with a long finger-like expansion; right palpomeres 1-2 (Fig. 1h), first one indistinct, second one sub-rectangular to square-like shaped, side about 25-30 $\mu \mathrm{m}$ long. Clypeus semicircular and bare. Thorax. Antepronotum (Fig. 1c) weakly developed with joined lobes. Antepronotals 3; acrostichals 4-5 starting close to antepronotum; dorsocentrals 5 in 1 row; prealars 2; scutellum with 8 setae. Wing. Brachiolum with 1 seta; number of setae on veins: $R, 7 ; R_{2+3}, 6-7$; remaining veins and squama bare. Legs. Femur of PI-PIII broad (100-110 $\mu \mathrm{m}$ maximum width); tibial spurs distinctly conspicuous and curved at apex, length ( $\mu \mathrm{m})$ : PI, 40; PII, 65; PIII, 55. Tarsomeres ta 3 and $\mathrm{ta}_{4}$ of PI and PIII (45 and $40 \mu \mathrm{m}$ long) shorter than tarsomere $\operatorname{ta}_{5}$ (75 and 65) as in Table 1; SV of PIII (9.48) is much higher than in PI and PII. Sensilla chaetica present on tibia and tarsomere ta ${ }_{1}$ of PI- 


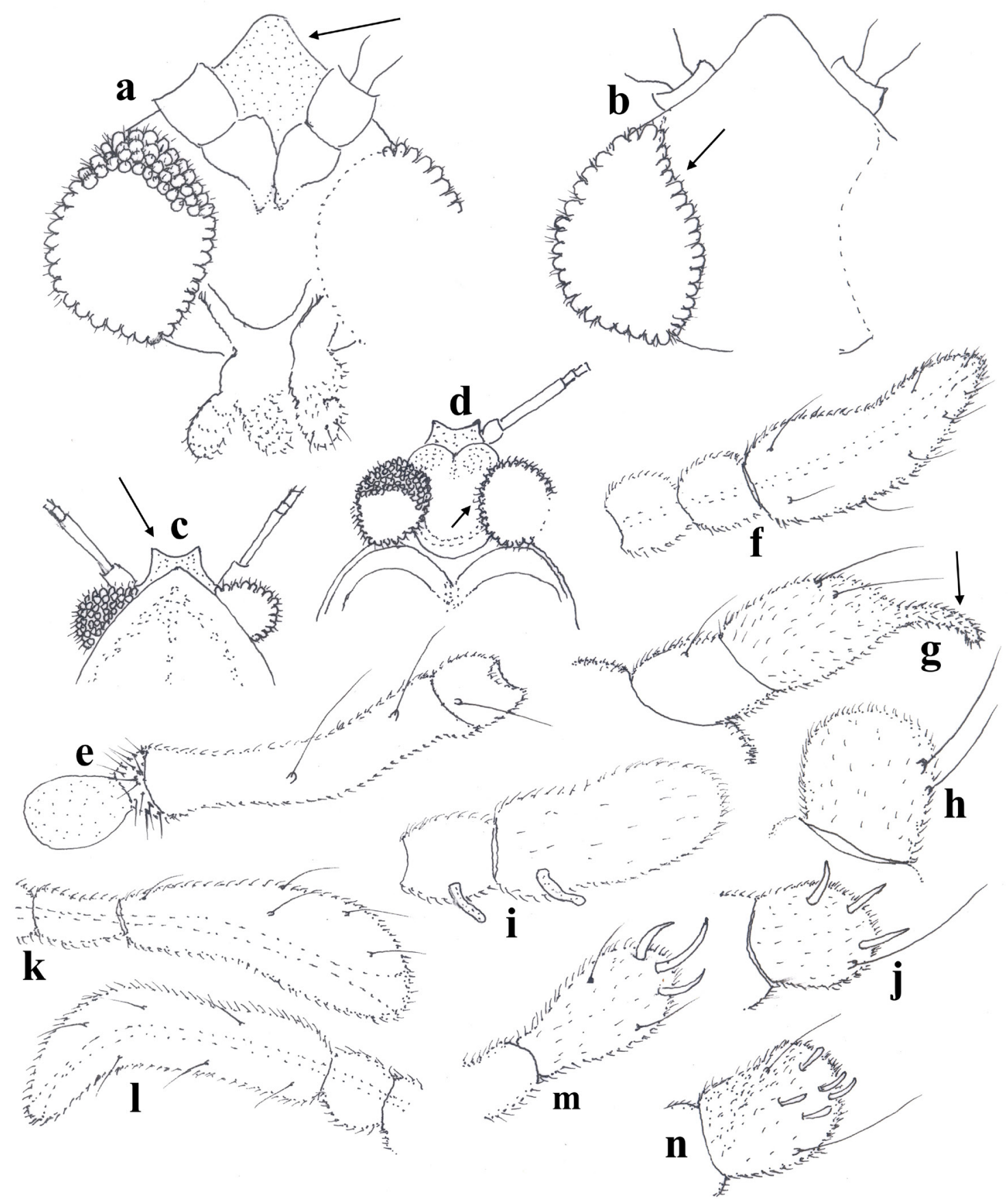

Figure 1. Male and female adults of Clunio spp. Male adult. Head in dorsal and ventral view of: a-b) C. marinus; c-d) C. boudouresquei sp. n. C. boudouresquei sp. n.: e) antenna, segments 1-3; f) segments 8-9 and last flagellomere; g) palp, left and right (h). Female adult of $C$. boudouresquei sp. n.: i) segment 6 and last flagellomere; j) palp. Male adult. Segment 9 and last flagellomere of: k) C. boudouresquei sp. n.; 1) C. marinus. Male adult. Palp of: m) C. sp. 2; n) C. marinus.

PIII. Length $(\mu \mathrm{m})$ and proportions of prothoracic (PI), mesothoracic (PII) and metathoracic (PIII) legs as in Table 1.

Abdomen. Hypopygium in dorsal and ventral view as in Figs 2a-b (Fig. 2a, dorsal; Fig. 2b, ventral, with tergite IX removed). Laterosternite absent. Tergite VIII with a distinct elongate ellipsoidal ridge located antero-medially, midline area bearing 6 short setae ( 3 on each side). Tergite IX is Clunio-type, without anal point; dorsal side (Fig. 2a) densely covered with macrotrichia-like setae in reclinate pattern (orally directed), postero-median area with about 40 short setae about $15 \mu \mathrm{m}$ long; ventral side (Fig. 3b) with a semi-circular posterior lamella covered with macrotrichia. Ventral side 
of hypopygium (Fig. 1b) includes 4 distinct apodemes (basal, axial, lateral and caudal) which can be detailed as: basal apodeme (= sternapodeme) $140 \mu \mathrm{m}$ maximum width, T-like shaped (Figs 1b, $3 a)$ with anterior side concave (occasionally convex as in Fig. 3c); axial apodeme about $320 \mu \mathrm{m}$ long, ending with a bi-lobed semi-circular apical expansion (Figs 2a, 3b); lateral apodeme (= phallapodeme) $250 \mu \mathrm{m}$ long, inwardly bent distally; caudal apodeme (Fig. 2b) distinctly branched on each lateral side, composed of 2 connected parts, basal one is rectangular brush-like shaped, posterior one consists of 5-6 grouped claws of typical structure. Gonocoxite about $600 \mu \mathrm{m}$ long, $250 \mu \mathrm{m}$ maximum width, distal inner area with dense group of long and short setae; inferior volsella $220 \mu \mathrm{m}$ long, 15 $20 \mu \mathrm{m}$ width medially, located distally, conical and densely covered with short and upwardly directed setae. Gonostylus (Figs 2c-d) inversed trianglelike shaped, arched with acute posterior angle and projecting backwards posteriorly; thicker at base, much thinner in median and distal parts; length (in $\mu \mathrm{m}$ of sides): basal one about 20 , concave one 25 , convex one 17; apical angle (Fig. 2d) with 1 single characteristic finger-like tubercle; crista dorsalis well-developed, consists of 2 unequal lobes occupying the entire length of gonostylus; megaseta tooth-like shaped and conspicuous, nearly as high as wide $(12-15 \mu \mathrm{m})$, represents an unusual character in the genus Clunio.

\section{Female adult}

$(\mathrm{n}=2,1$ pharate; Figs $1 \mathrm{i}-\mathrm{j}, 4 \mathrm{a}-\mathrm{e})$

Small sized species. Total length 1.65-1.70 mm. General shape is Clunio female-type. Colouration as in the male adult except for the thorax, which is less dark. Antennae light brown; legs brownish with blackish claws. Abdominal tergites and anal segment contrasting brown to dark brown. Head.
Eyes densely hairy, sub-circular without dorsomedian extension, hairs absent on inner lateral eye margin, outer posterior margin lacking setae. Temporals 2 , including 1 inner and 1 outer vertical. Clypeus semi-circular, bare. Antenna 7-segmented, about $200 \mu \mathrm{m}$ long; last flagellomere (Fig. 1i) 60 $\mu \mathrm{m}$ long, elongated and lobe-like; segments 6 and 7 each with 1 tubular sensilla chaetica; antennal groove reaching segment 2; AR 0.43. Palp (Fig. 1j) 2-segmented; segment 1, indistinct; palpomere 2, globular about $20 \mu \mathrm{m}$ long bearing 3 sensilla clavata distally and 1 long fine seta. Thorax. Chaetotaxy indistinct. Legs. Tibia of PI, PII and PIII nearly equal $(185,180,185 \mu \mathrm{m}$ long); length $(\mu \mathrm{m})$ of tibial spurs of: PI, 40; PII, 65; PIII, 5. Tarsomeres $\mathrm{ta}_{1}-\mathrm{ta}_{5}$ of PI and PII equal in size as in Table 2; tarsomeres ta tand $_{1}$ of PI and PIII are globular and equal in size (40 $\mu \mathrm{m}$ long each); tarsomere ta of PI and PII (40 $\mu \mathrm{m}$ long) is half long as ta ${ }_{1}$ of PIII $(85 \mu \mathrm{m})$. Femur of PI is much wider $(90 \mu \mathrm{m})$ than in PII-PIII (70 and 60); tibia of PIII is wider (55 $\mu \mathrm{m})$ than in PI and PII (45 $\mu \mathrm{m}$ each); tarsomere ta of PII is much wider $(50 \mu \mathrm{m})$ than in PI and PIII (27 $\mu \mathrm{m}$ each); tarsomere ta ${ }_{1}$ of PII is wider $(55 \mu \mathrm{m})$ than in PI and PIII (30 $\mu \mathrm{m}$ each). LR value (Table 2) of PIII (0.46) is much higher than those of PI and PII (0.22 each); SV value (Table 2) of PI and PII (10.75 and 11) is about twice of PIII (5.35). Sensilla chaetica present in low number on tibia and tarsomere ta ${ }_{1}$ of PI, PII and PIII. Length (in $\mu \mathrm{m})$ and proportions of prothoracic (PI), mesothoracic (PII) and metathoracic (PIII) legs as in Table 2.

Abdomen. Anal segment (dorsal, Fig. 4a; ventral, Fig. 4b) $280 \mu \mathrm{m}$ long, $260 \mu \mathrm{m}$ maximum width at base, $130 \mu \mathrm{m}$ wide at caudal part. Genitalia in dorsal and ventral view as illustrated in Figs $4 b-$ e. Notum about $140 \mu \mathrm{m}$ long with separate rami; on each side the rami are connected to a sternal

Table 1. Male adult of Clunio boudouresquei sp. n. Length $(\mu \mathrm{m})$ and proportions of prothoracic (PI), mesothoracic (PII) and metathoracic (PIII) legs.

\begin{tabular}{c|c|c|c|c|c|c|c|c|c|c|c}
\hline & $\mathbf{f e}$ & $\mathbf{t i}$ & $\mathbf{t a}_{\mathbf{1}}$ & $\mathbf{t a}_{\mathbf{2}}$ & $\mathbf{t a}_{\mathbf{3}}$ & $\mathbf{t a}_{\mathbf{4}}$ & $\mathbf{t a}_{\mathbf{5}}$ & $\mathbf{L R}$ & $\mathbf{B V}$ & $\mathbf{S V}$ & $\mathbf{B R}$ \\
\hline PI & 475 & 615 & 160 & 50 & 45 & 40 & 75 & 0.26 & 5.95 & 6.81 & 0.90 \\
\hline PII & 555 & 555 & 200 & 95 & 115 & 55 & 70 & 0.36 & 3.91 & 5.55 & 0.75 \\
\hline PIII & 610 & 575 & 125 & 50 & 45 & 40 & 65 & 0.22 & 6.55 & 9.48 & 0.80 \\
\hline
\end{tabular}

Table 2. Female adult of Clunio boudouresquei sp. n. Length $(\mu \mathrm{m})$ and proportions of prothoracic (PI), mesothoracic (PII) and metathoracic (PIII) legs.

\begin{tabular}{cccccccccccc}
\hline & $\mathbf{f e}$ & $\mathbf{t i}$ & $\mathbf{t a}_{\mathbf{1}}$ & $\mathbf{t a}_{\mathbf{2}}$ & $\mathbf{t a}_{\mathbf{3}}$ & $\mathbf{t a}_{\mathbf{4}}$ & $\mathbf{t a}_{\mathbf{5}}$ & $\mathbf{L R}$ & $\mathbf{B V}$ & $\mathbf{S V}$ & $\mathbf{B R}$ \\
\hline PI & 245 & 185 & 40 & 25 & 20 & 15 & 40 & 0.22 & 4.7 & 10.75 & 0.80 \\
\hline PII & 260 & 180 & 40 & 25 & 20 & 15 & 40 & 0.22 & 4.8 & 11 & 0.85 \\
\hline PIII & 270 & 185 & 85 & 35 & 40 & 20 & 45 & 0.46 & 3.86 & 5.35 & 0.90 \\
\hline
\end{tabular}




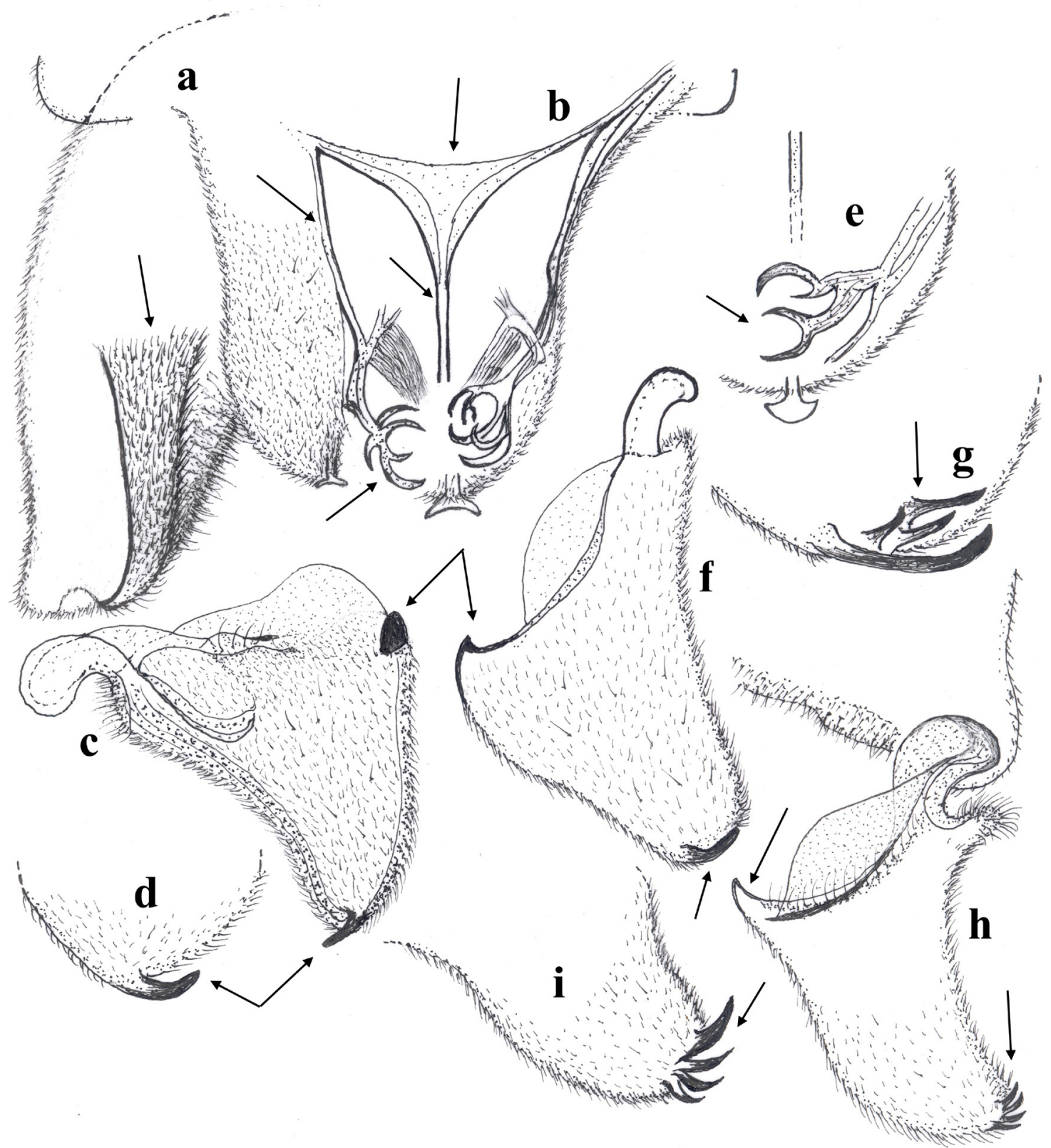

Figure 2. Male adult of Clunio spp. C. boudouresquei sp. n.: a) hypopygium, tergite IX and inferior volsella, dorsal; b) basal, lateral, axial and caudal apodemes, ventral view; c) gonostylus dorsal; d) gonostylus, apical part. $C$. mediterraneus: e) caudal apodemes of hypopygium, ventral; f) gonostylus, dorsal. C. sp. 1: g) apex of gonostylus. C. marinus: h) gonostylus, dorsal; i) apical part.

axial apodeme. Sternite VIII with 22-24 setae (1112 on each side of the notum). Gonapophysis VIII (Figs 4b-d): dorsomesal lobe (Fig. 4d) convex medially and projecting in both proximal and apical parts; ventrolateral lobe directed downwards, broader basally and narrowing posteriorly; apodeme lobe (left, Fig. 4c) distinctly swollen in its postero-median part. Presence of 2 stout inwardly directed setae on each side of gonapophysis VIII between base of sternite VIII and ventrolateral lobe. Seminal capsules $70 \mu \mathrm{m}$ long, $40 \mu \mathrm{m}$ maximum width, sub-oval and well-sclerotized medially. Spermathecal ducts with loops and separate openings. Tergite IX (Fig. 4e) egg-like shaped, markedly divided, with 20-22 setae (10-11 on each side). Gonocoxite (Figs 4a-b) weekly developed but widely extended, bearing 8-9 setae. Cercus (Fig. 4b) sub-rectangular, normally developed and projecting upwards.

\section{Pupal exuviae}

$(\mathrm{n}=10,7$ males and 3 females; Figs 5a, 5c, 5e-f)

Total length 2.85-3.15 mm. Colouration contrasting dark brown to yellow brown, wrinkles present on antero-median area of frontal apotome and tho- 

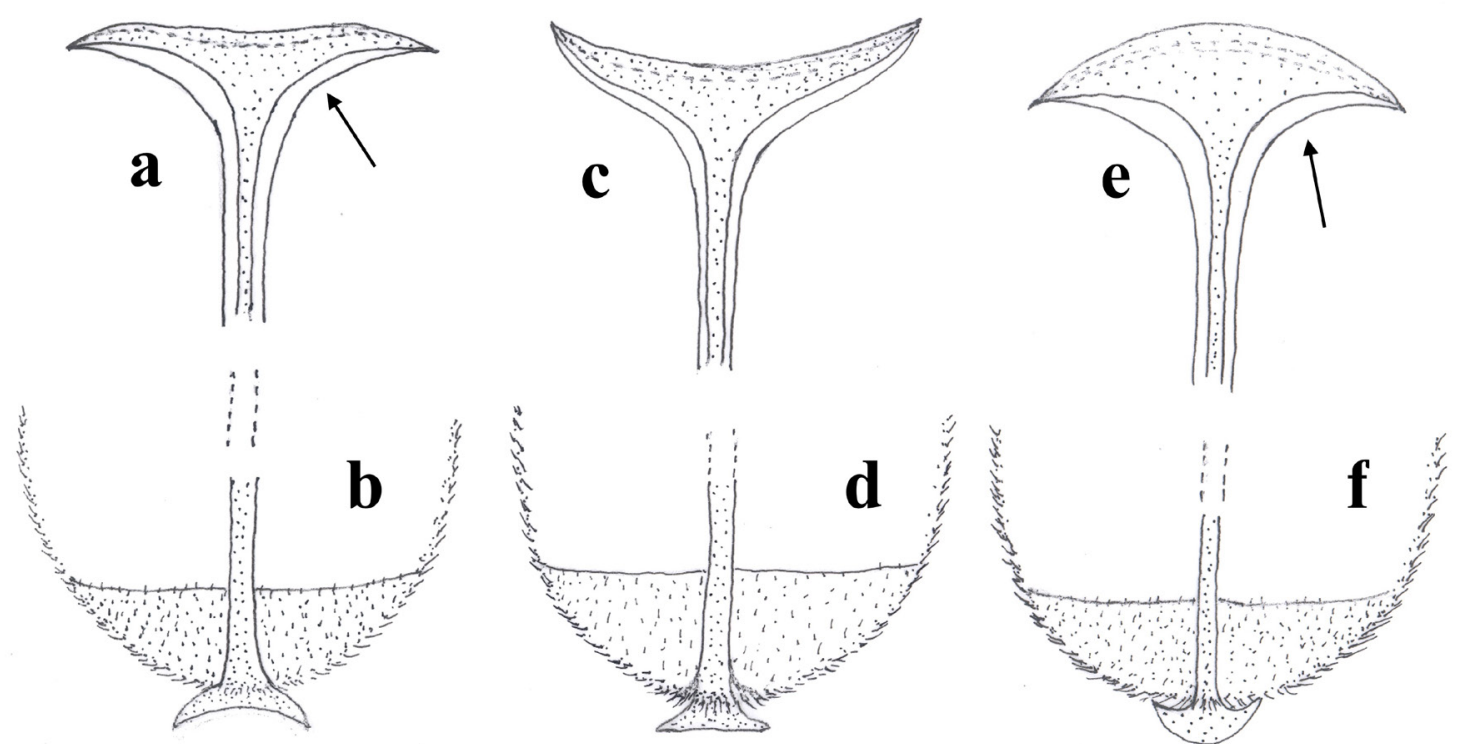

Figure 3 a-f). Male adult of Clunio spp. Axial apodeme and distal part of tergite IX of: a-b) C. boudouresquei sp. n.; c-d) C. mediterraneus; e-f) C. sp. 1.
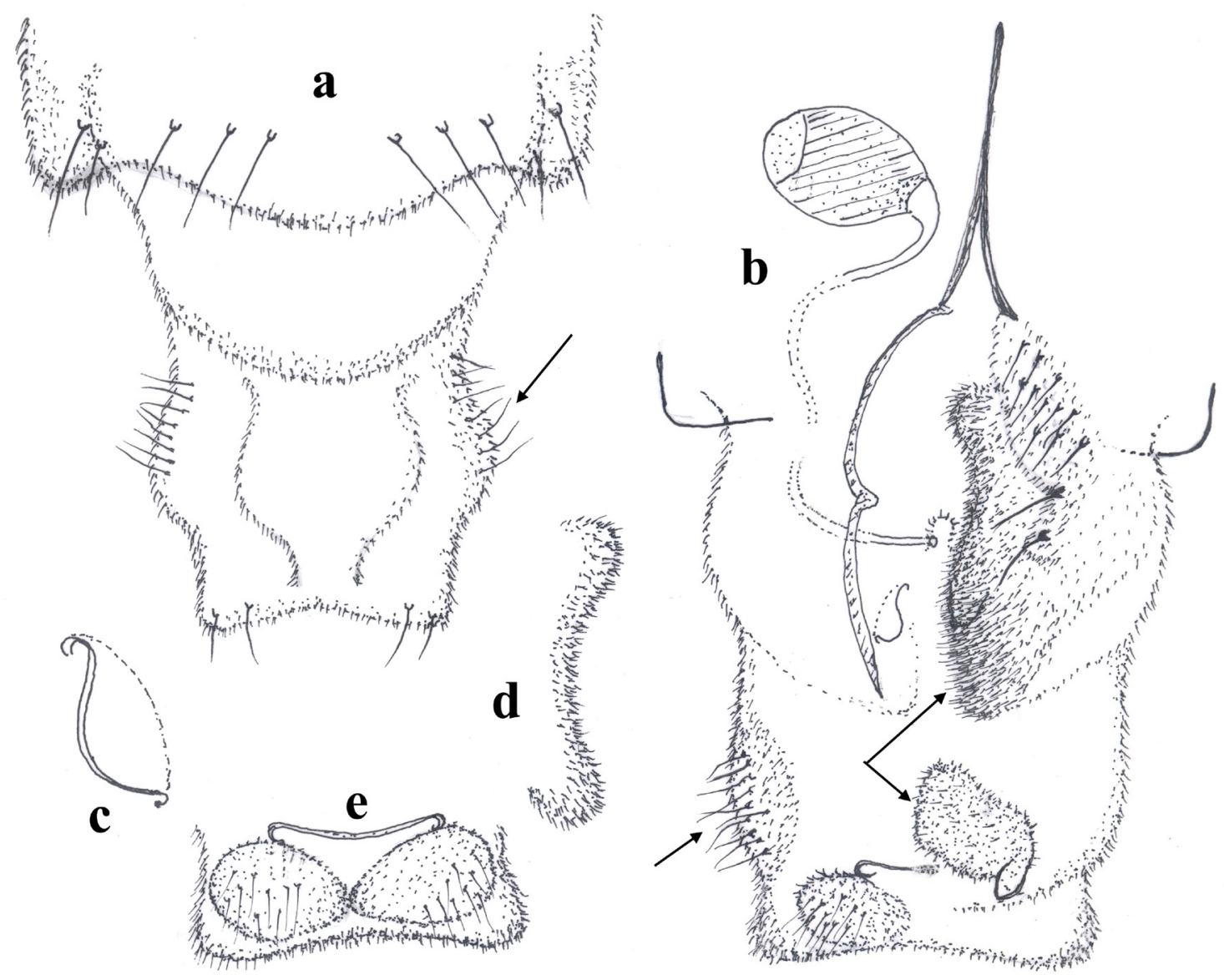

Figure 4. Female adult of Clunio boudouresquei sp. n. a) tergites VIII-IX with gonocoxites, dorsal; b) genitalia with gonapophysis VIII, sternite VIII, seminal capsule, gonocoxite, tergite IX and cercus; c) apodeme lobe; d) dorsomesal lobe; e) tergite IX, dorsal. 
rax; abdomen and anal segment brownish. Cephalothorax. Frontal apotome broadly trapezoidal, frontal setae about $40 \mu \mathrm{m}$ long, inserted posteromedially, distance between frontal setae $50 \mu \mathrm{m}$. Median antepronotals nearly subequal (30-35 $\mu \mathrm{m}$ long), lateral antepronotal absent; precorneals subequal, about $50 \mu \mathrm{m}$ long, insertion arranged I, triangle. Dorsocentrals $\mathrm{Dc}_{1}-\mathrm{Dc}_{2}$ and $\mathrm{Dc}_{3}-\mathrm{Dc}_{4}$ located close together; $\mathrm{Dc}_{4}$ subequal (about 10-15 $\mu \mathrm{m}$ long), $\mathrm{Dc}_{3}$ and $\mathrm{Dc}_{4}$ sub-equal (about $40 \mu \mathrm{m}$ long); distance (in $\mu \mathrm{m}$ ) between: $\mathrm{Dc}_{1}$ to $\mathrm{Dc}_{2} 30, \mathrm{Dc}_{2}$ to $\mathrm{Dc}_{3} 80, \mathrm{Dc}_{3}$ to $\mathrm{Dc}_{4} 10$.

Abdomen. Armament, chaetotaxy, distribution pattern of shagreen and details of armament on tergites and sternites II-VII as in Figs 5a, 5c, 5e-f. Tergite I and sternites I-III bare, sternite IV occasionally with 1-2 rows of small spines (Fig. 5a). Conjunctives of tergites III-VII and sternites V-VII with one transverse row of hooks, which are smaller on sternites, conjunctive on segment VIII composed only of short posteriorly directed spines. Antero-median transverse rows of spines present on tergites II-VII, sparsely present and interrupted medially on tergite II, becoming denser and more extensive on tergites III-VI. Pedes spurii A and B absent; apophyses on tergites and sternites absent. Number and distribution pattern of lateral setae on segments I-VIII: 2 on segment I; $2 / 3$ on II-VII; 3 on VIII. Anal segment is Clunio-type, genital sac 490-500 $\mu \mathrm{m}$ long, $70 \mu \mathrm{m}$ maximum width, ending each with 1 pointed tubercle.

\section{Larva}

Known but not described.

\section{Differential diagnosis}

Male adult and pupal exuviae of $C$. boudouresquei sp. n. are compared to those of known Clunio species from seacoasts of Europe and neighbouring areas, based on material collected by the senior author in Corsica, continental France, Italy, Spain except for Bulgaria (Varna seashores, leg. P. Michailova). Some relevant specific features found in the male adult and pupal exuviae will easily separate the new species from other members of Clunio by the following combination of characters:

Male adult: Frontal area of head bearing 2 apical projections (Figs 1c-d), is differently shaped in $C$. marinus (Figs 1a-b); last flagellomere narrowed apically (Fig. 1f), is widely clubbed in C. mediterraneus (Fig. 1k) and linearly curved in $C$. $\mathrm{sp}$. 1 (Fig. 11); typical long finger-like expansion of left palp (Fig. 1g), is absent in both C. sp. 2 (Fig. $1 \mathrm{~m}$ ) and C. marinus (Fig. 1n); caudal apodeme composed of basal brush-like and 5-6 apical claws
(Fig. 2b), is lacking basal brush and less branched apically in C. mediterraneus (Fig. 2e); megaseta present on gonostylus (Fig. 2c), is absent in $C$. mediterraneus (Fig. 2f) and C. marinus (Fig. 2h); apex of gonostylus with only one single finger-like tubercle (Figs 2c-d), while consists of several unequal tubercles in both $C$. sp. 1 (Fig. $2 \mathrm{~g}$ ) and $C$. marinus (Figs 2h-i); basal and apical parts of axial apodeme (Figs 3a-b), are differently shaped in $C$. mediterraneus (Figs 3c-d and C. sp. 1 (Figs 3e-f).

Male pupal exuviae: Transverse row of hooks present on sternites V-VII (Figs 5a, 5e-f), only present on sternites V-VI in C. mediterraneus (Figs 5b, 5gh); anteromedian rows of spines on tergite II interrupted medially and sparse (Fig. 5c), is continuous and more dense in C. mediterraneus (Fig. 5d).

\section{Ecology and remarks}

The immature stages of Clunio spp. are typically marine dwellers of the intertidal zone along the littoral and mid-littoral zones of rocky shores, sometimes in association with populations of Mytilus spp. In some species (in particular those associated with Lithophyllum beds) the emergence of the adults is synchronized with the lunar cycle (Neumann 1976, Neumann et al. 1997, Kaiser \& Heckel 2012). The biological cycle (reproduction and emergence) of C. boudouresquei sp. n. is closely related to the typology of the intertidal zone including alternation between submerged marine habitats and terrestrial ecological conditions, which are strongly reinforced during spring tides of lunar rhythms (new and full moon).

The pavements, 'trottoirs' of L. byssoides represent a combination of habitats that typically characterize the intertidal zone of the protected area of Scandola Nature Reserve. They mainly consist of a pristine combination of habitats considered to be microrefugia for a dense and diversified community of marine, semi-aquatic and semi-terrestrial species, including members of several closely integrated dipteran families (Chironomidae, Ceratopogonidae and Dolichopdidae). The newly described species is encountered in the marine mid-littoral zone of Punta Palazzu (Fig. 6), where larval stages occur exclusively within the large bio-constructions of the 'long-living' red calcified alga $L$. byssoides, which clearly delimit alternate cycles of both submerged and terrestrial habitats. In addition, the bio-concretions of Punta Palazzu are currently considered as the largest Lithophyllum beds in Europe, where valuable knowledge on the biology (growth rate) and ecology of the algal communities are documented by Verlaque (2010). 


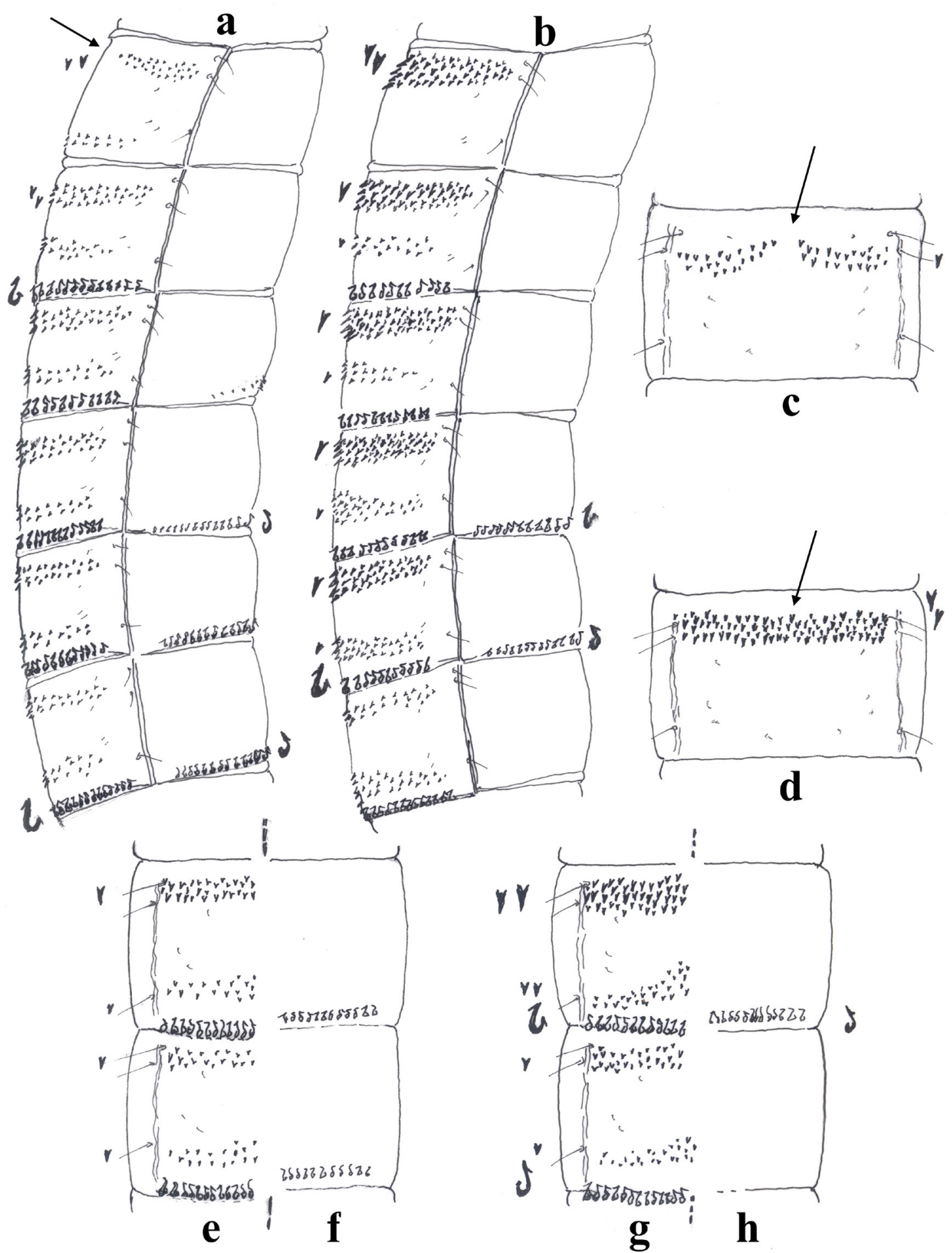

Figure 5. Pupal exuviae of Clunio spp. Distribution pattern, chaetotaxy and details of armament of abdominal segments II-VII of: a) C. boudouresquei sp. n.; b) C. mediterraneus. Tergite II (dorsal) of: c) C. boudouresquei sp. n.; d) C. mediterraneus. Tergite VI-VII (dorsal and ventral) of: e-f) C. boudouresquei sp. n.; g-h) C. mediterraneus. 
While the biological and ecological quality of $L$. byssoides rims are still well-preserved at Punta Palazzu and Port-Cros Island (Figs 6-7), other similar marine sites located along the coastal Mediterranean ecosystem of continental France are becoming extinct, or have been deeply damaged and degraded (Figs 8-9) during the last four decades by human activities, including ecotourism and release of toxic chemical pollutants (e.g., HAP, PCB, abundance of macro- and microplastics). In addition, the L. byssoides beds delimited by the latter endangered sites, are heavily threatened by a massive proliferation of an invasive Mytilidae species (Mytilus galloprovincialis Lamarck, 1819). This sea mussel significantly predominates when changes in water quality and level of pollution become increasingly high (seashores at Banyuls, SW-France, Figs 8-9), where populations are intensely enlarging and reinforcing their potential expansion in occupying up to $70-80 \%$ of the living $L$. byssoides original cover. Such situations are also highlighted in southern France by Blanfuné et al. (2019) for the 'Canopy-forming Seaweeds' of Cystoseira mediterranea Sauvageau, 1810, where an important decline of local populations with risk of extinction are reported; Linares et al. (2010) and Garragou et al. (2017) report a similar scenario for the Mediterranean Red Coral, suggesting that constructive plans and management measures for conservation and preservation of autochthonous Tyrrhenian elements must be implemented.
Consequently, in some of the Tyrrhenian mid-littoral coastlines (Punta Palazzu, Port-Cros, Banyuls), some relevant and vulnerable Clunio species are closely confined to the Lithophyllum beds, and therefore their loss would be clearly indicative of a combination of anthropogenic impacts and global warming in this geographical region. Such relict Tyrrhenian species are considered as potentially biogeographic representatives and biological indicators of local climate change (in particular, the rise of sea level), which strongly affect both sustainability and viability of the Clunio populations.

\section{Geographical distribution}

Geographical distribution of known Clunio species from European seacoasts (Ashe \& O'Connor 2012) and the Tyrrhenian sub-region is given in in Figure 10. Clunio boudouresquei sp. $\mathrm{n}$. ' abundant at the type-locality of Punta Palazzu (Scandola Nature Reserve, West Corsica); weakly represented in southern France (Port-Cros and Porquerolles Islands, Cassis, Banyuls). Occurrences of $C$. boudouresquei sp. n. in southern France indicate that it may be more widespread in other geographical areas of the Tyrrhenian sub-region (insular and continental Provinces), and therefore can be expected from the seacoasts of some neighbouring countries like Italy and Spain. Clunio marinus ' $*$ ' is found along all Atlantic seacoasts in Europe including France, Germany, England, Iceland, Ireland, Italy, Madeira, Netherland, Norway,

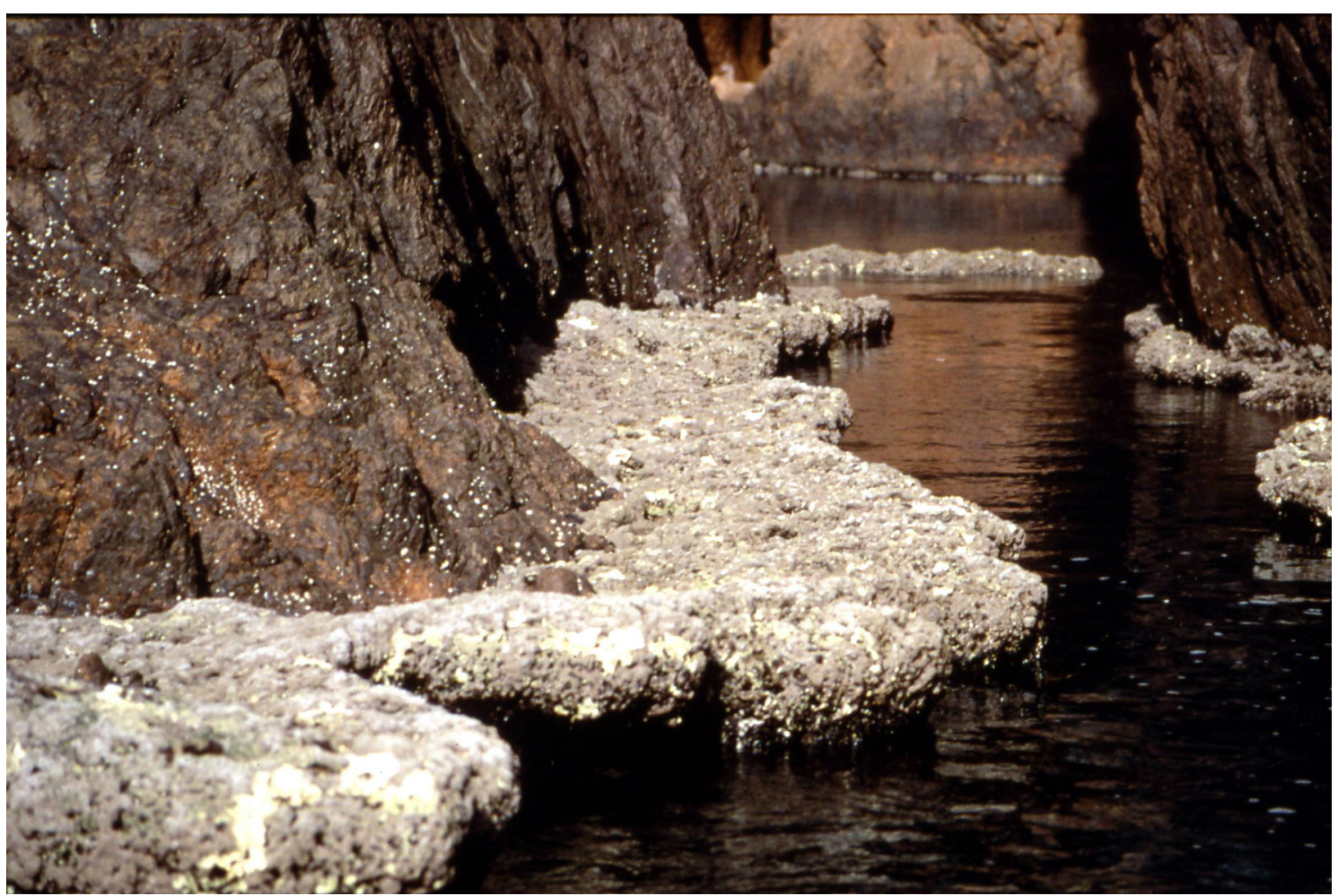

Figure 6. Large bio-constructions of the red calcified alga Lithophyllum byssoides at Punta Palazzu (Scandola Nature Reserve, W-Corsica). Type locality of Clunio boudouresquei sp. n. Photo J. Moubayed-Breil. 


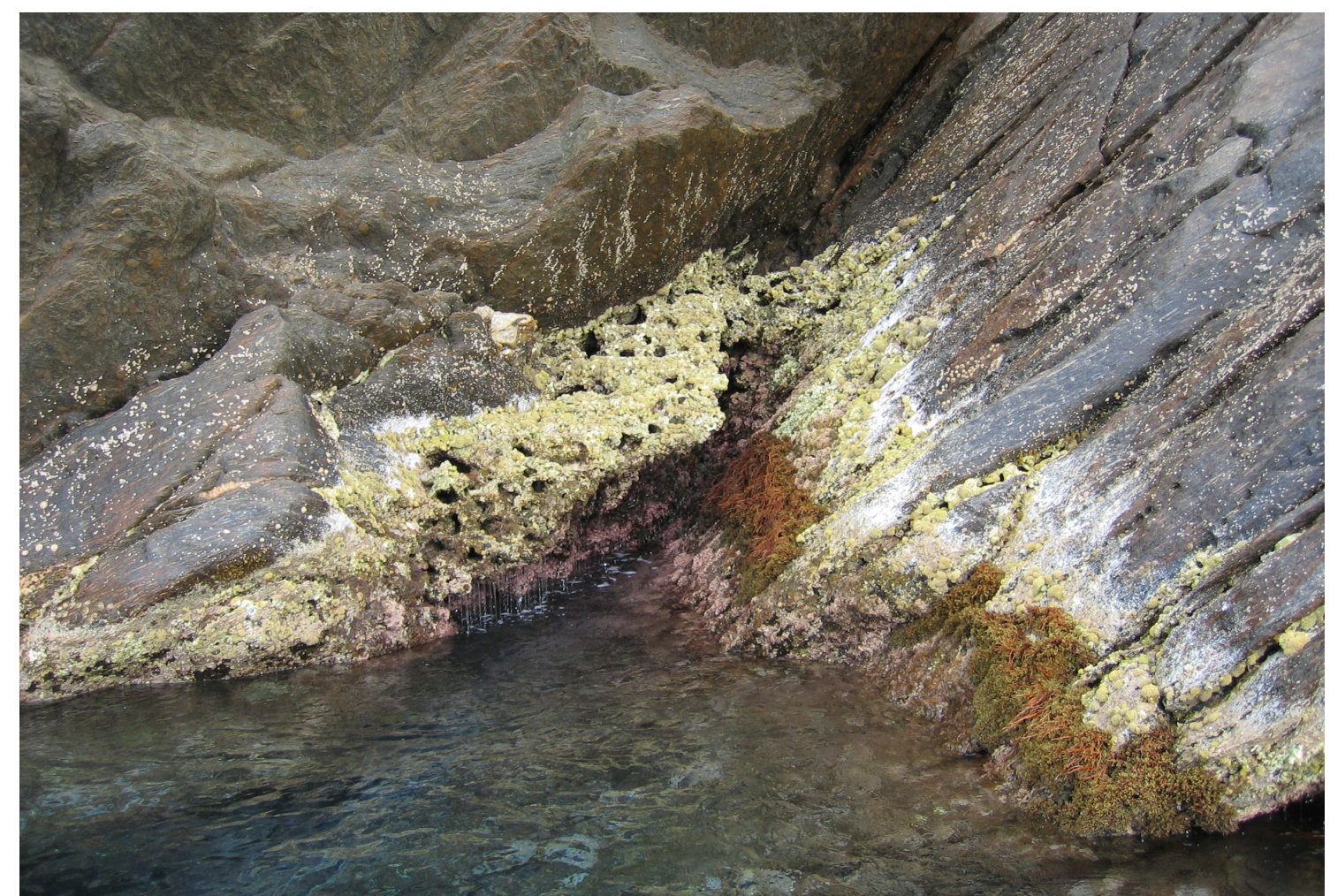

Figure 7. Bio-constructions of the red calcified alga Lithophyllum byssoides at Port-Cros Island (SE-France). Photo S. Ruitton.

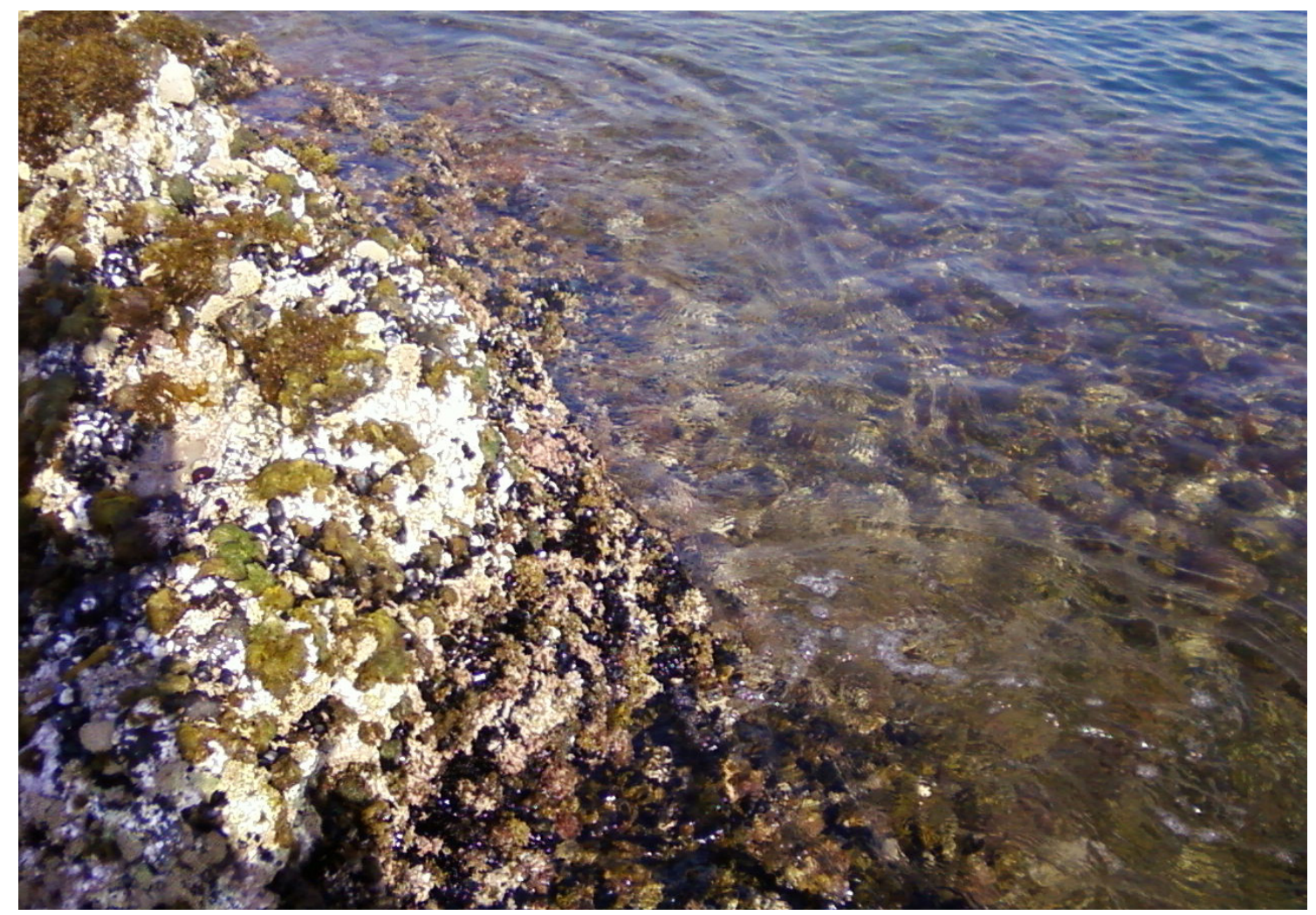

Figure 8. Threatened bio-constructions of Lithophyllum byssoides by the massive proliferation of Sea Mussels at Banyuls Seashores (SW-France): level-1. Photo J. Moubayed-Breil. 


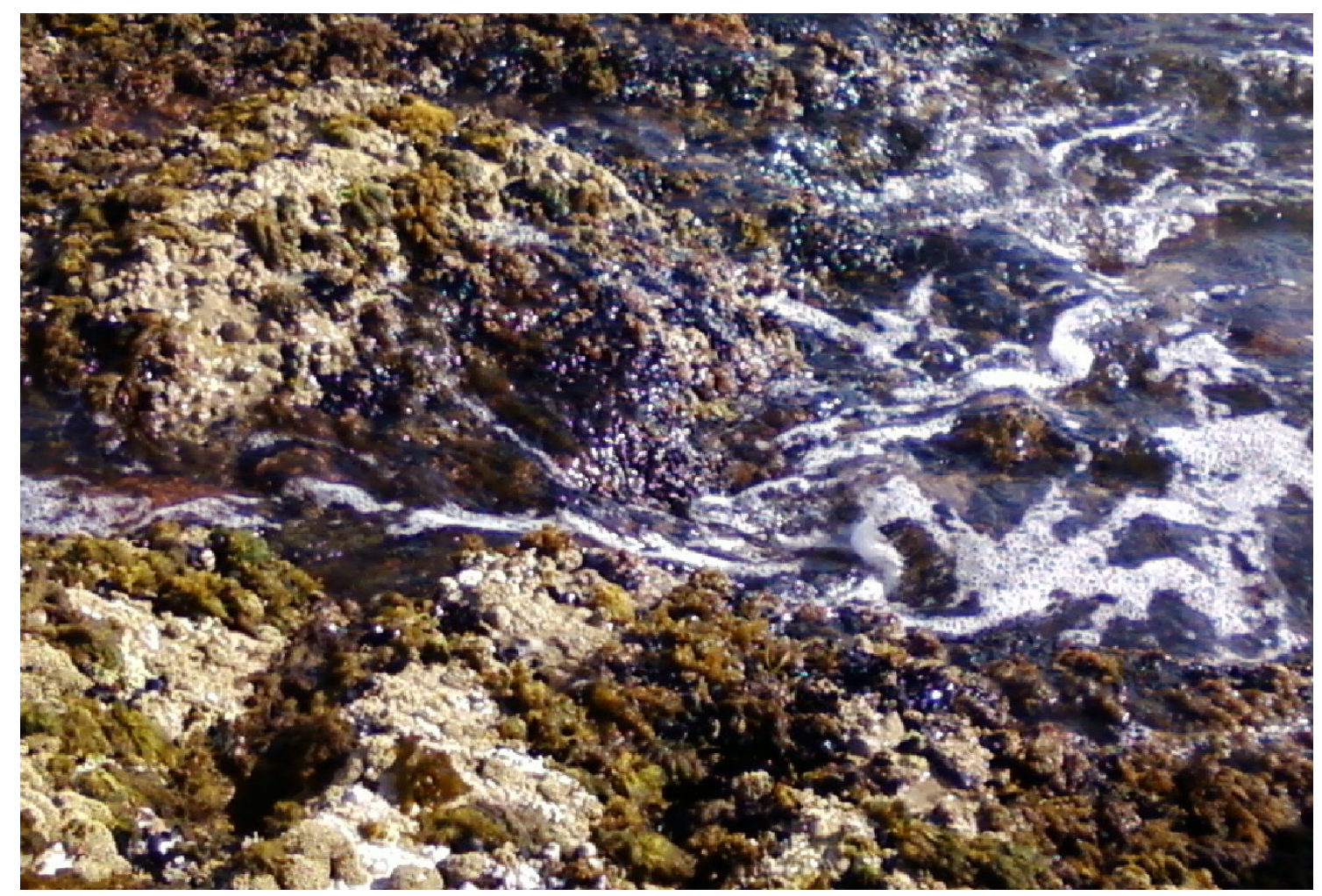

Figure 9. Threatened bio-constructions of Lithophyllum byssoides by the massive proliferation of Sea Mussels at Banyuls Seashores (SW-France): level-2. Photo J. Moubayed-Breil.

Spain and Sweden. Clunio mediterraneus ' $*$ ' is widespread in the Mediterranean Basin: Southern France (Cerbère, Banyuls, Sète, Carry, Marseille, Cassis, Port-Miou, Hyère, Porquerolles, Port-Cros, Nice), northern and western Corsica, the Balearic Islands, Italy, Spain, Turkey, Croatia (the Adriatic Sea). Clunio ponticus Michailova, 1980 ' $\bullet$ ' is only recorded from the Black Sea (Varna, Bulgaria).

Thalassosmittia ballestai Moubayed-Breil, sp. n.

Thalassosmittia sp. 1, in Moubayed-Breil \& Ashe (2012), Moubayed Breil et al. (2013).

\section{http://zoobank.org/0C9795ED-02C6-47BB-A8A1- 190480BE9EEA}

\section{Material examined}

Holotype. France, West Corsica, Scandola Nature Reserve, Focolara Bay (Fig. 14), $42^{\circ} 21^{\prime} 25^{\prime \prime} \mathrm{N}, 8^{\circ} 34^{\prime} 0^{\prime \prime} \mathrm{E}$; 1 male pharate adult, leg. J. Moubayed-Breil, 03.VI.2015. Locality No. 31 in Moubayed-Breil \& Ashe (2012), locality No. 30 in Moubayed-Breil et al. (2013). Marine water temperature: $10-12^{\circ} \mathrm{C}$ (min.), $22-24^{\circ} \mathrm{C}$ (max.).

Paratypes (all leg J.M-B.): 3 pupal exuviae (2 males and 1 female), same locality as for holotype, 03.VI.2015.

Holotype (mounted on 1 slide) and 2 pupal exu- viae ( 1 male and 1 female) are deposited in the collections of the Zoologische Staatssammlung München (ZSM), Munich, Germany. Additional paratypes are deposited in the senior author's collection.

\section{Diagnostic characters}

Though the pupal exuviae of T. ballestai sp. n. apparently shows a close morphological resemblance with that of $T$. thalassophila (distribution pattern of armament on tergites and shape of anal lobe), some relevant specific characters found in the male adult (shape of tergite IX, anal point and inferior volsella) will sufficiently separate the species described here from other related members of genus Thalassosmittia by the below listed characters.

Male adult: Temporals with 3 inner and 3 verticals; last flagellomere of antenna distinctly clubbed, abruptly narrowing distally and bearing a brush of curved sensilla chaetica; antennal groove reaching segments 2, AR 0.72; lobes of antepronotum widely opened; antepronotals absent. Brachiolum with 1 seta, veins and squama bare. Tarsomere ta of PI-PII wider and rounded apically; spurs present on tarsomeres $\mathrm{ta}_{1}-\mathrm{ta}_{4}$; sensilla chaetica present on tibia and tarsomeres $\mathrm{ta}_{1}-\mathrm{ta}_{4}$ of PI-PIII. Tergite anal band absent on tergite IX; anal point drop-like shaped and bearing a rounded setiferous lobe at 


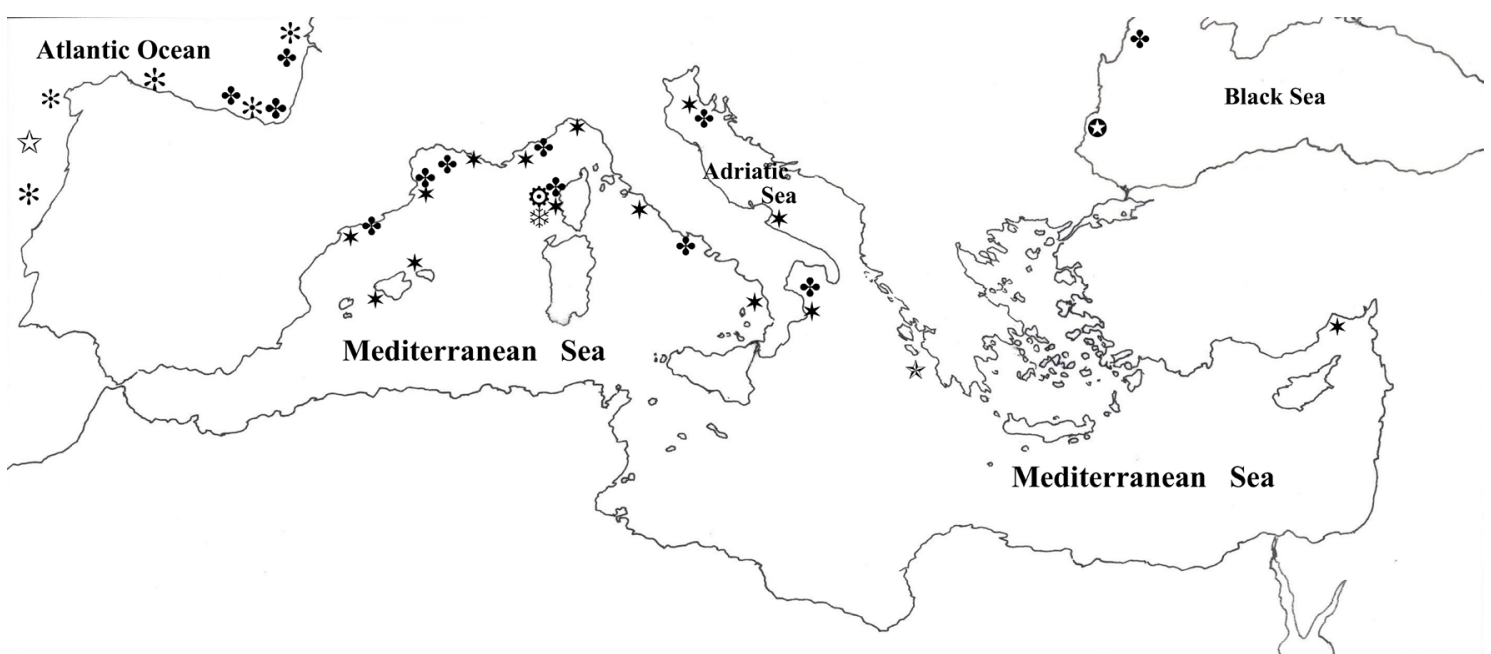

Figures 10. Clunio spp. and Thalassosmittia spp. Geographical distribution of known species from the Mediterranean basin and neighbouring seacoasts: C. boudouresquei sp. n., ; . marinus, *; C. mediterraneus, *; C. ponticus, $\mathbf{*}$; . atlantica, , T. ballestai sp. n., T. thalassophila, *.

base; virga with 2 closely grouped spines; inferior volsella rounded lobe-like shaped with bifid basal margin; gonostylus distinctly swollen at base and thinner distally when viewed laterally.

Pupal exuviae: Frontal apotome with sub-cylindrical tubercles; dorsocentral Dc distances between dorsocentral $\mathrm{Dc}_{1}$ vestigial about 5-7 $\mu \mathrm{m}$ long; $\mathrm{Dc}_{1}$ and $\mathrm{Dc}_{2}$ separated by $25 \mu \mathrm{m}, \mathrm{Dc}_{2}$ and $\mathrm{Dc}_{3}$ by $70 \mu \mathrm{m}$; transverse row of hooks and orally directed pins present on conjunctives of sternites IV/V-VII/VIII is occasionally absent on IV/V; anal lobe sub-trapezoidal, genital sac distinctly swollen distally and bearing an apical finger-like tubercle. Pedes spurii A and Pedes spurii B absent. Anal lobe sub-trapezoidal to sub-triangular, bearing 2 subequal macrosetae on dorsal side; genital sac swollen distally, bearing a projecting outwards tubercle.

Etymology: the new species is named 'ballestai' in honour of our colleague Laurent Ballesta (Andromède Océanologie, Carnon, South France) who is still an active marine biologist studying and preserving the Mediterranean marine fauna and flora including the protected area of Scandola Nature Reserve, which represents a precious and valuable inheritance area.

\section{Male adult}

$(\mathrm{n}=2,1$ pharate; Figs 11a, 11c-h, 12a)

Total length 1.55-1.60 mm. Wing length 1.05-1.10 $\mathrm{mm}$. Colouration variable in general, contrasting from light brown to brown even to greenish; Head, antenna, halters and legs light brown; thorax with mesonotal stripes contrasting light brown to brown; anal segment and inferior volsella distinctly contrasting brown to hyaline; wing translucent. Head. Eyes bare between ommatidia, nearly circular with dorso-median extension; inner lateral margin bare. Vertex and coronal area (Fig. 11a) distinctly triangular and orally projecting, basal and median margins of coronal triangle much thicker than distal part, coronal setae absent. Temporals uniserial including 3 inner and 2 outer verticals. Clypeus semicircular to sub-rectangular, with about $16-18$ setae in 3-4 rows. Palp-5 segmented, segments 1-2 fused, length $(\mu \mathrm{m})$ of palpomeres 1-5: 15, 25, 47, 63, 80; third palpomere with 2 sensilla clavata and 3 sensilla coeloconica located distally. Antenna $550 \mu \mathrm{m}$ long; last flagellomere $230 \mu \mathrm{m}$ long, distinctly clubbed distally, distal half abruptly narrowing and bearing a brush of curved sensilla chaetica; antennal groove reaching segments 2; AR 0.72. Thorax. Lobes of antepronotum (Fig. 11c) widely opened; antepronotals absent; acrostichals 26 in 1-2 rows; dorsocentrals 9 in 1 row; prealars 3; supraalars absent. Humeral pit indistinct. Scutellum semicircular, with 4 uniserial setae. Wing. Brachiolum with 1 seta. Veins and squama bare. Legs. Tarsomere ta $_{5}$ of PI-PII wider in its distal part and rounded apically; tibial spurs of PI-PIII spiniform; spurs present on tarsomeres $\mathrm{ta}_{1}-\mathrm{ta}_{4}$. Sensilla chaetica present in low number on tibia and tarsomeres $\mathrm{ta}_{1}-\mathrm{ta}_{4}$ of PI-PIII: on $\mathrm{ta}_{1}-\mathrm{ta}_{4}$ (proximally and distally); only distally on tibiae. Length $(\mu \mathrm{m})$ and proportions of prothoracic (PI), mesothoracic (PII) and metathoracic (PIII) legs as in Table 3.

Abdomen. Hypopygium in dorsal, ventral and lateral view as in Figs 11e-f, 12a (Fig. 11e, dorsal; Fig. 11f, ventral with tergite and anal point removed; Fig. 12a, lateral). Tergite IX semicircular, posterior area with a dark circular setiferous band located close to the base of anal point, which is 


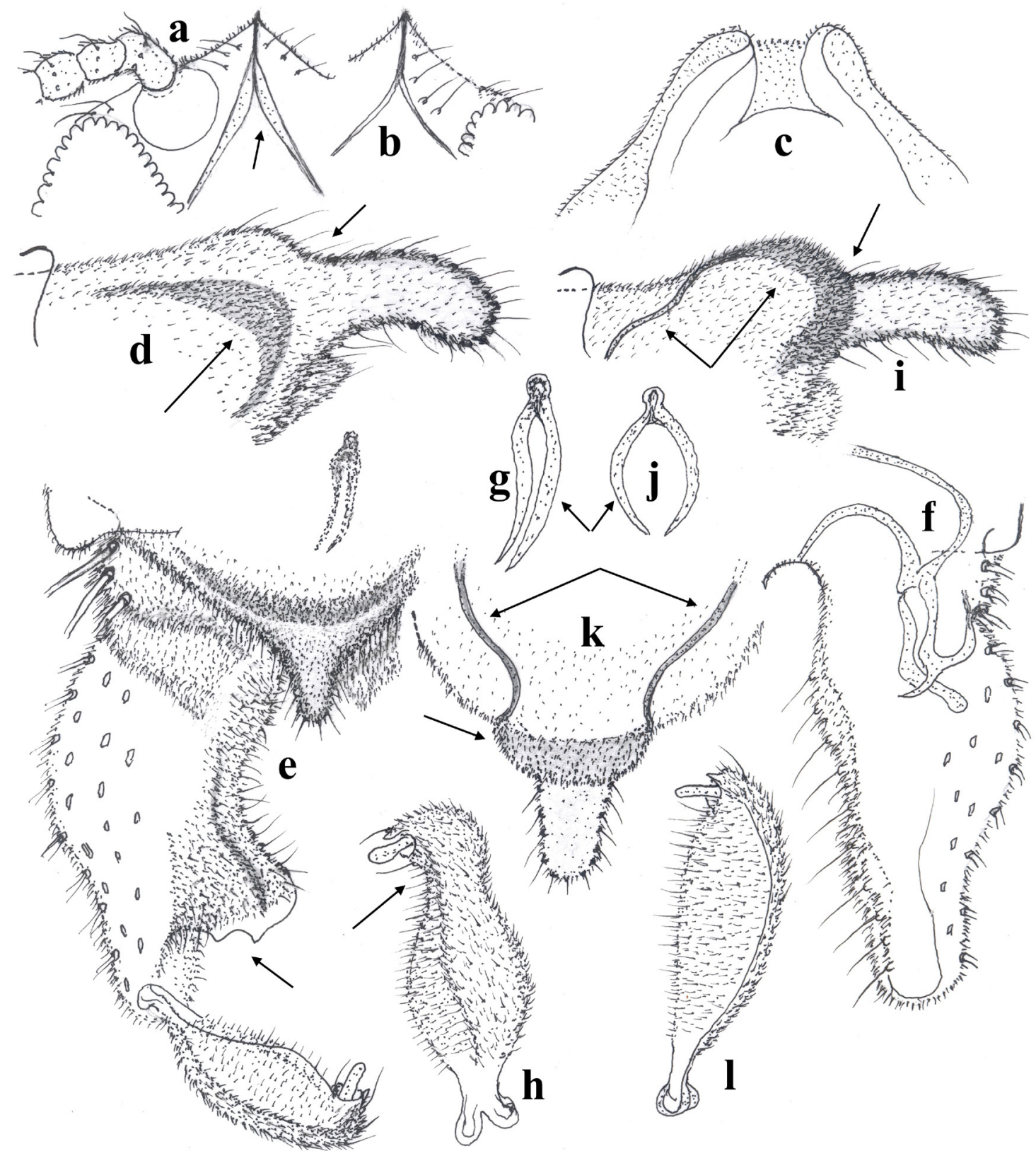

Figure 11. Male adult of Thalassosmittia spp. Vertex with coronal triangle of: a) T. ballestai sp. n.; b) T. thalassophila. T. ballestai sp. n.: c) lobes of antepronotum; d) tergite IX and anal point, lateral; e) hypopygium, dorsal; f) hypopygium, ventral view with tergite and anal point removed); g) virga; h) gonostylus, lateral. T. thalassophila: i) tergite IX and anal point, lateral; j) virga; k) anal point, dorsal; 1) gonostylus, lateral.

clearly visible in lateral view (Fig. 11d). Anal point (Figs 11d, 11e, 12a) about 40-45 $\mu \mathrm{m}$ long, 70-75 $\mu \mathrm{m}$ maximum width at base; broadly triangular at base and drop-like shaped in its remaining part; lateral and apical margins densely covered with setae. Laterosternite IX with 6 setae (3 on each side). Sternapodeme, transverse sternapodeme and phallapodeme as in Fig. 11f, basal part orally projecting, basal part of coxapodeme semicircular and projecting inwards. Virga (Figs 11e, 11g) about $40 \mu \mathrm{m}$ long, consists of 2 long curved spines.
Gonocoxite about $265 \mu \mathrm{m}$ long, $75 \mu \mathrm{m}$ maximum width, much wider at base, narrowing distally to a rounded apex, inner margin with 10-11 stout setae. Inferior volsella large lobe-like shaped, rounded apically with posterior margin distinctly bi-lobed, apical and caudal parts contrasting and hyaline. Gonostylus in dorsal (Fig. 11e) and lateral view (Fig. 11h) $105 \mu \mathrm{m}$ long, $30 \mu \mathrm{m}$ maximum width; swollen medially and less wide distally when view laterally; posterior margin sinuous and swollen medially; crista dorsalis low and widely extended 
Table 3. Male adult of Thalassosmittia ballestai sp. n. Length $(\mu \mathrm{m})$ and proportions of prothoracic (PI), mesothoracic (PII) and metathoracic (PIII) legs.

\begin{tabular}{c|c|c|c|c|c|c|c|c|c|c|c}
\hline & $\mathbf{f e}$ & $\mathbf{t i}$ & $\mathbf{t a}_{\mathbf{1}}$ & $\mathbf{t a}_{\mathbf{2}}$ & $\mathbf{t a}_{\mathbf{3}}$ & $\mathbf{t a}_{\mathbf{4}}$ & $\mathbf{t a}_{\mathbf{5}}$ & $\mathbf{L R}$ & $\mathbf{B V}$ & $\mathbf{S V}$ & $\mathbf{B R}$ \\
\hline PI & 350 & 445 & 205 & 110 & 85 & 50 & 60 & 0.46 & 3.28 & 3.89 & 2.10 \\
PII & 460 & 420 & 245 & 135 & 80 & 60 & 50 & 0.58 & 3.46 & 3.59 & 2.80 \\
PIII & 495 & 430 & 215 & 115 & 75 & 60 & 55 & 0.50 & 3.74 & 4.30 & 2.60 \\
\hline
\end{tabular}

is clearly visible only in dorsal view; megaseta present and well-developed.

\section{Pupal exuviae}

$(\mathrm{n}=5,2$ males and 3 females; Figs $12 \mathrm{c}, 12 \mathrm{e}-\mathrm{k}$, $13 \mathrm{a}, 13 \mathrm{e})$

Total length 1.65-1.70 mm. General colouration contrasting brown to dark brown; frontal apotome with anterior half covered with fine wrinkles; antero-median area of cephalothorax and suture of thorax markedly rugulose and wrinkled; abdomen yellowish to pale, anal lobe and genital sac brown to dark brown. Cephalothorax as in Figs 12c and 13a; frontal apotome (Fig. 13a) triangular with pointed lateral expansions; frontal tubercles about 40-45 $\mu \mathrm{m}$ high, sub-cylindrical and well-developed, frontal setae about $70 \mu \mathrm{m}$ long, separated by $25-30 \mu \mathrm{m}$. Thorax as in Fig. 12c. Median antepronotal nearly subequal (90 and 80-85 $\mu \mathrm{m}$ long), lateral antepronotal and prealars absent; precorneals 85,80 and $90 \mu \mathrm{m}$ long. Dorsocentrals consist of 3 unequal setae, length (in $\mu \mathrm{m}$ ) of $\mathrm{Dc}_{1}-\mathrm{Dc}_{3}$ : $\mathrm{Dc}_{1}$, vestigial about $5-7 ; \mathrm{Dc}_{2}, 55 ; \mathrm{Dc}_{3}, 70$; distance (in $\mu \mathrm{m})$ between: $\mathrm{Dc}_{1}$ to $\mathrm{Dc}_{2} 25, \mathrm{Dc}_{2}$ to $\mathrm{Dc}_{3} 70$.

Abdomen. Armament, chaetotaxy and distribution pattern of shagreen with details of armament on tergites and sternites: III-VIII (Fig. 12e); V-VII (Figs 12f-k). Tergite I and sternites I-IV bare. Anterior transverse rows of spines present on tergites II-VIII, those on tergites VII-VIII are smaller and less extensive; posterior transverse rows of spines present on tergites III-VIII, becoming gradually more extensive on VI-VIII. Conjunctives of tergites III/IV-VII/VIII and sternites IV/V-VII/VIII with rows of hooks and orally directed pin-shaped setae (Figs 12e, 12h-k), those on sternite IV/V are occasionally absent (Fig. 12g). Caudo-lateral area of tergites and sternites II-VII with a group of short spines (Figs 12e-k). Pedes spurii A and PSB absent. Number and distribution pattern of lateral setae on segments I-VII, 2, postero-lateral seta on segments V-VI forked; segment VIII with 3 setae located distally. Anal segment in dorsal and ventral view as in Fig. 13e; anal lobe sub-trapezoidal to sub-triangular, $130-135 \mu \mathrm{m}$ long, $135-140 \mu \mathrm{m}$ minimum width at base, $185-190 \mu \mathrm{m}$ maximum width at apex, a rounded patch of short spine present medially, apex bearing a finger-like tubercle which is projecting outwards; genital sac $220 \mu \mathrm{m}$ long, distinctly swollen distally and overreaching apical margin of anal lobe by 70-75 $\mu \mathrm{m}$; macrosetae consist of 2 subequal setae, about 90-95 $\mu \mathrm{m}$ long, separated by about $35-40 \mu \mathrm{m}$.

\section{Larva}

Unknown.

\section{Differential diagnosis}

Only the pupal exuviae of T. ballestai sp. n. directly key close to those of $T$. thalassophila, while the male adult is quite different and likely belongs to a local 'Tyrrhenian element'. On the basis of some relevant specific characters found in the male adult and pupal exuviae, T. ballestai sp. n. is compared, as male adult, to that of $T$. thalassophila and, as pupal exuviae, to other undescribed morphotypes collected in Corsica, continental France, Italy and Spain. However, T. ballestai sp. $\mathrm{n}$. is easily distinguished from other related species or taxa/species of Thalassosmittia by the following combination of characters.

Male adult: Head with 3 inner verticals (Fig. 11a), is bearing 4 in T. thalassophila (Fig. 11b); tergite anal band absent on tergite IX (Figs 11d-e), is conspicuously present in T. thalassophila (Figs 11i, $11 \mathrm{k}$ ); anal point drop-like shaped and much wider at base (Fig. 11e), is parallel-sided with semicircular basal part in T. thalassophila (Fig. 11k); virga with 2 closely grouped spines (Figs 11e, 11g), consist of 2 inwardly curved spines and horseshoe-shaped in T. thalassophila (Fig. 11j); inferior volsella rounded lobe-like shaped with bifid basal margin (Figs 11e, 12a ), is divided in 2 separate parts in T. thalassophila (Fig. 12b); gonostylus in lateral view (Fig. 11h), is differently figured in $T$. thalassophila (lateral, Fig. 111).

Male pupal exuviae: Frontal apotome with subcylindrical tubercles (Fig. 13a), are smaller and fused apically in T. thalassophila (Fig. 13b), weakly domed in T. marinus (Fig. 13c) and conical in T. sp. 1 (Fig. 13d); distances between dorsocentral $\mathrm{Dc}_{1}$ to $\mathrm{Dc}_{2}$ and $\mathrm{Dc}_{2}$ to $\mathrm{Dc}_{3}$ are respectively 


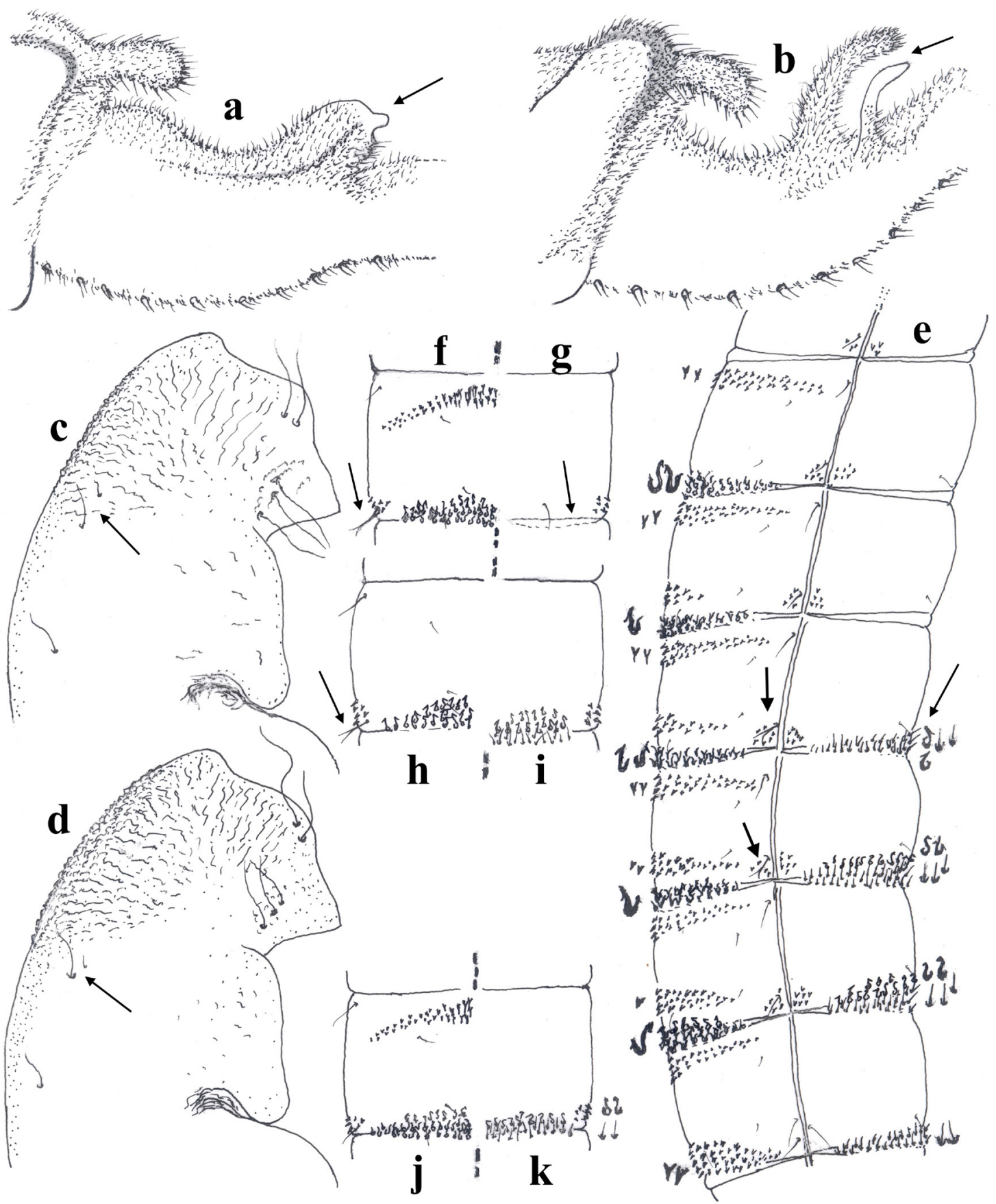

Figure $12 \mathrm{a}-\mathrm{k})$. Male adult and pupal exuviae of Thalassosmittia spp. Anal point and inferior volsella in lateral view of: a) T. ballestai sp. n.; b) T. thalassophila. Cephalothorax of: c) T. ballestai sp. n.; d) T. thalassophila. T. ballestai sp. n.: e) chaetotaxy and details of armament on abdominal segments III-VIII; f-g) tergite $\mathrm{V}$ in dorsal and ventral view; h-i) tergite VI in dorsal and ventral view; $\mathrm{j}-\mathrm{k}$ ) tergite VII in dorsal and ventral view.

25 and 70 (Fig. 12c), while are 15 and 55 in $T$. thalassophila (Fig. 12d); transverse row of hooks and orally directed pins present on conjunctives of sternites V/VI-VII/VIII (Fig. 12e) or occasionally absent on IV/V (Fig. 12g), is regularly present on conjunctives of sternites IV/V-VII/VIII of $T$. thalassophila (couplet 196 in Langton 1991); anal lobe (Fig. 13e) sub-triangular to sub-trapezoidal, is distinctly triangular in T. thalassophila (Fig. 13f), semicircular in T. marinus (Fig. 13g), rectangular in $T$. sp. 1 (Fig. 13h) and sub-circular in T. sp. 2 (Fig. 13i); genital sac (Fig. 13e) distinctly swollen distally with an apical finger-like tubercle apically, is differently figured in T. thalassophila (Fig. 13f). 


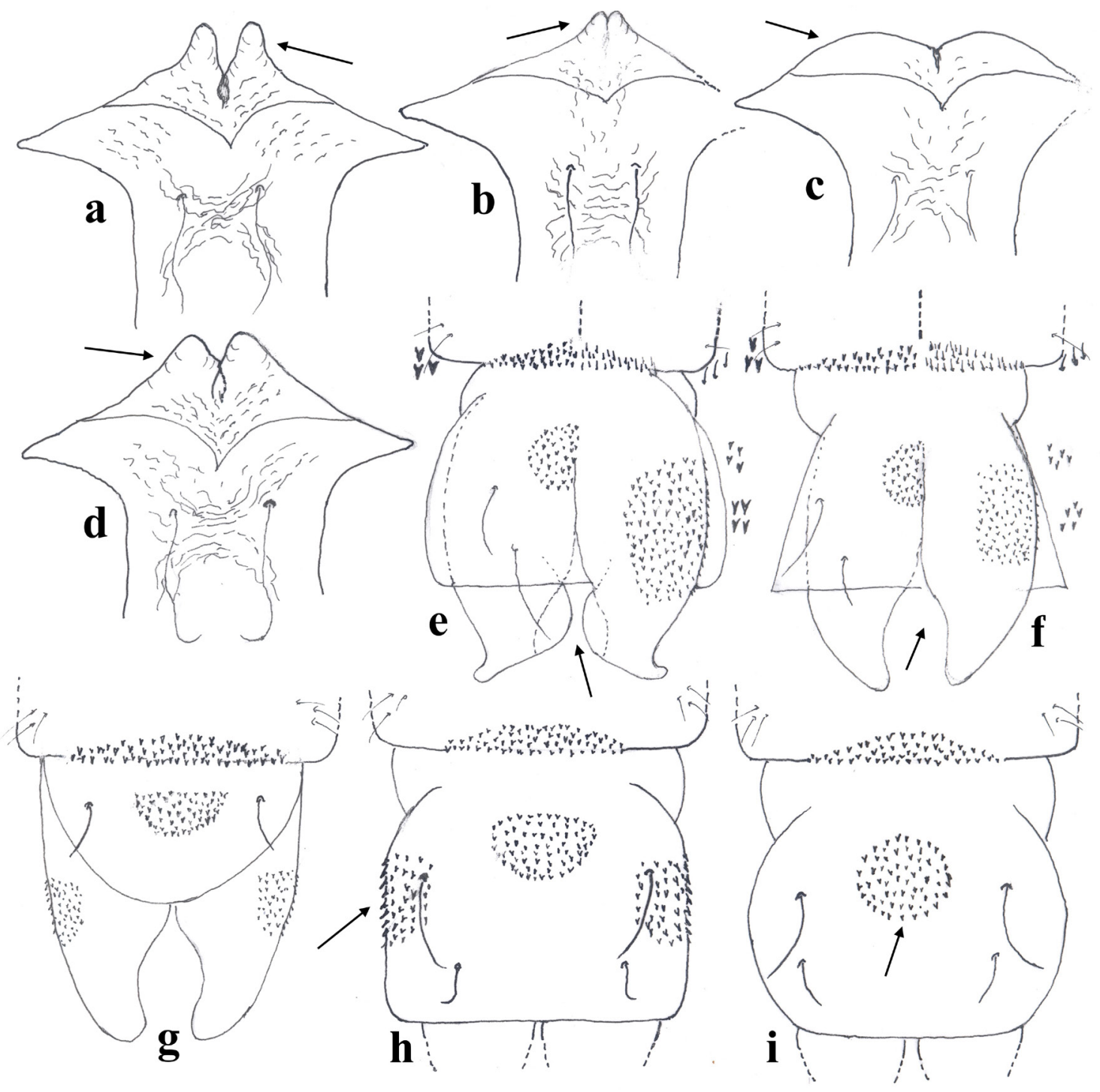

Figure 13. Pupal exuviae of Thalassosmittia spp. Frontal apotome of: a) T. ballestai sp. n.; b) T. thalassophila; c) T. marinus; d) T. sp. 1. Caudal armament of segment VIII and anal segment of: e) T. ballestai sp. n., dorsal and ventral; f) T. thalassophila, dorsal and ventral. Caudal armament of segment VIII and anal segment of: g) T. marinus; h) T. sp. 1; i) T. sp. 2.

\section{Ecology and remarks}

The examined material of T. ballestai sp. n. (male adults, male pharate adults and pupal were collected in the type locality of Focolara Bay (Fig. 14) located in Scandola Natural Reserve, western Corsica. Additional material including associated larval stages is needed to determine and confirm the ecology of the new described species. While the marine intertidal zone at Focolara Bay is better preserved during winter and spring periods, it still heavily degraded, as other seacoasts around the Mediterranean Basin, by the impact of pollution and ecotourism activities, which highly increase each year between June and September.
The increasing abundance of plastics along the coastal ecosystem, estuarine zones and the littoral marine environment of Corsica (Bastia, Ajaccio, Porto, etc.) including those of Scandola Nature Reserve, has been observed since the last three decades. Inorganic matter, composed of pellet tar and plastics, collected in both drift and troubleau nets (as shown and detailed in Figs 15-16), has become more dominant major threat to all types of marine organisms. Small particles of plastics, consisting of several forms of both macro- and micro-particles of $0.5-5$ to $10-15 \mathrm{~mm}$ size, are systematically found from the surface and water column to the seabed sediment and beach, where marine organisms (especially deposit feeders and detritivores) 


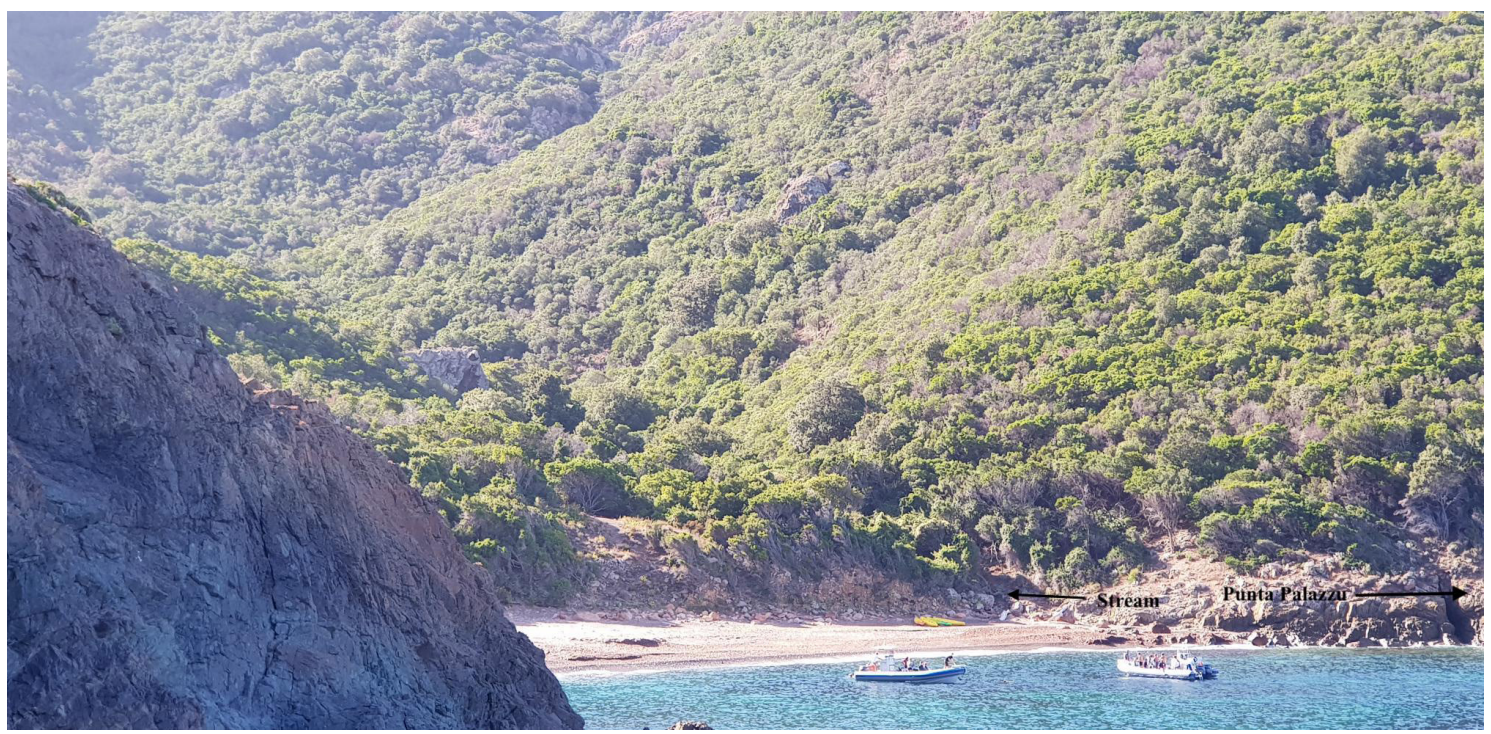

Figure 14. The Bay of Focolara at Scandola Nature Reserve, western Corsica. Type locality of Thalassosmittia ballestai sp. n. Photo J.M. Dominici.

ingest them. Therefore, these pollutants may adversely impact species that inhabit intertidal zones that cannot adapt to changing conditions via behavioural plasticity; T. ballestai may be among these species. Consequently, a major challenge in marine environmental disciplines (evolutionary biology, ecology, conservation) is to better understand and predict how these sensitive species will respond to the impact of human activities and the rise of sea level, which is directly related to the global warming.

\section{Geographical distribution}

Geographical distribution of known Thalassosmittia species from European seacoasts (Ashe \& O'Connor 2012) and the Tyrrhenian sub-region is given in figure 10. Thalasosmittia atlantica 's is known only from the western Atlantic seacoasts including the Canary Islands (type-locality), Madeira, Spain and Portugal. Thalasosmittia ballestai sp. n. ' is common and abundant in the seashores of Focolara Bay (West Corsica). The records of T. ballestai sp. n. (pupal exuviae) from some seashores in southern France need to be confirmed by the presence of associated material composed of adults and pupae. Thalasosmittia thalassophila 'of' is present along the Atlantic and some Mediterranean seacoasts in Europe including: France, England, Germany, Greece, Ireland, Italy, Netherland, Romania and Spain.

\section{Acknowledgements}

The authors are grateful to Dr. Alyssa Andersen (Southwest Minnesota State University, USA) and Dr. Torbjørn Ekrem (NTNU University Museum, Trondheim, Norway) for their constructive

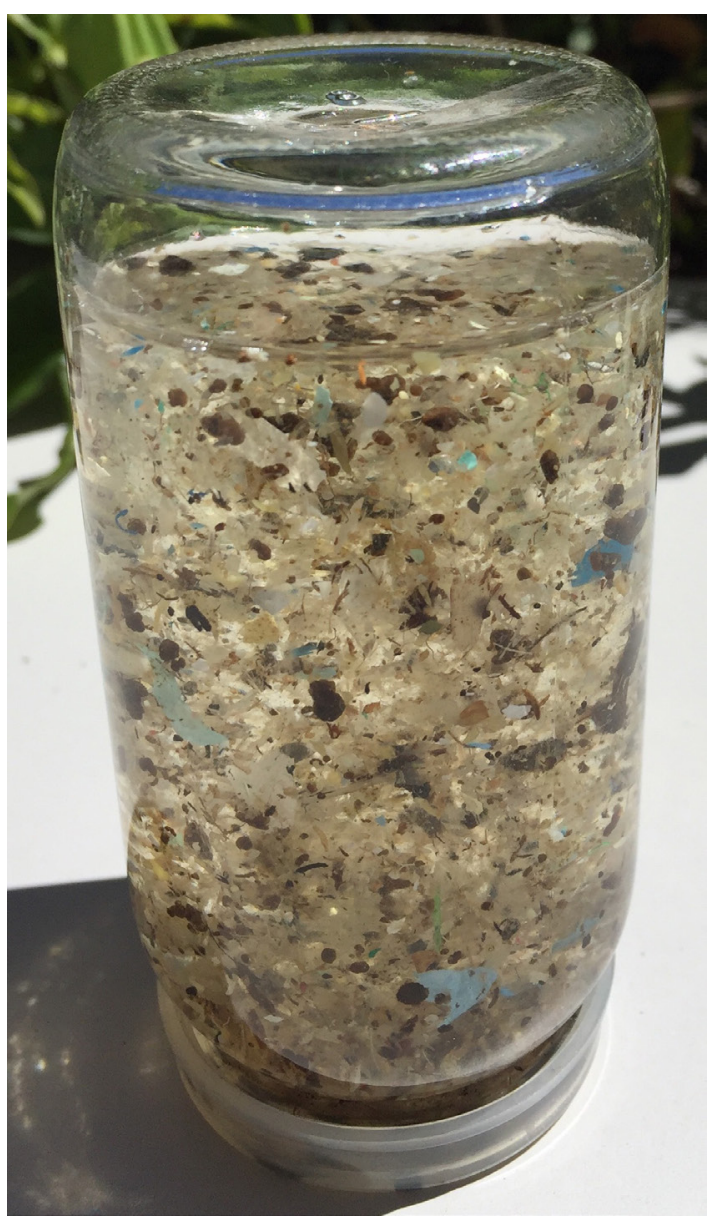

Figure 15. Plastics in the form of 'Macro- and Micro-particles' (1-5 to $10-15 \mathrm{~mm}$ size), collected at Focolara Bay, Scandola Nature Reserve. Photo J. Moubayed-Breil. 


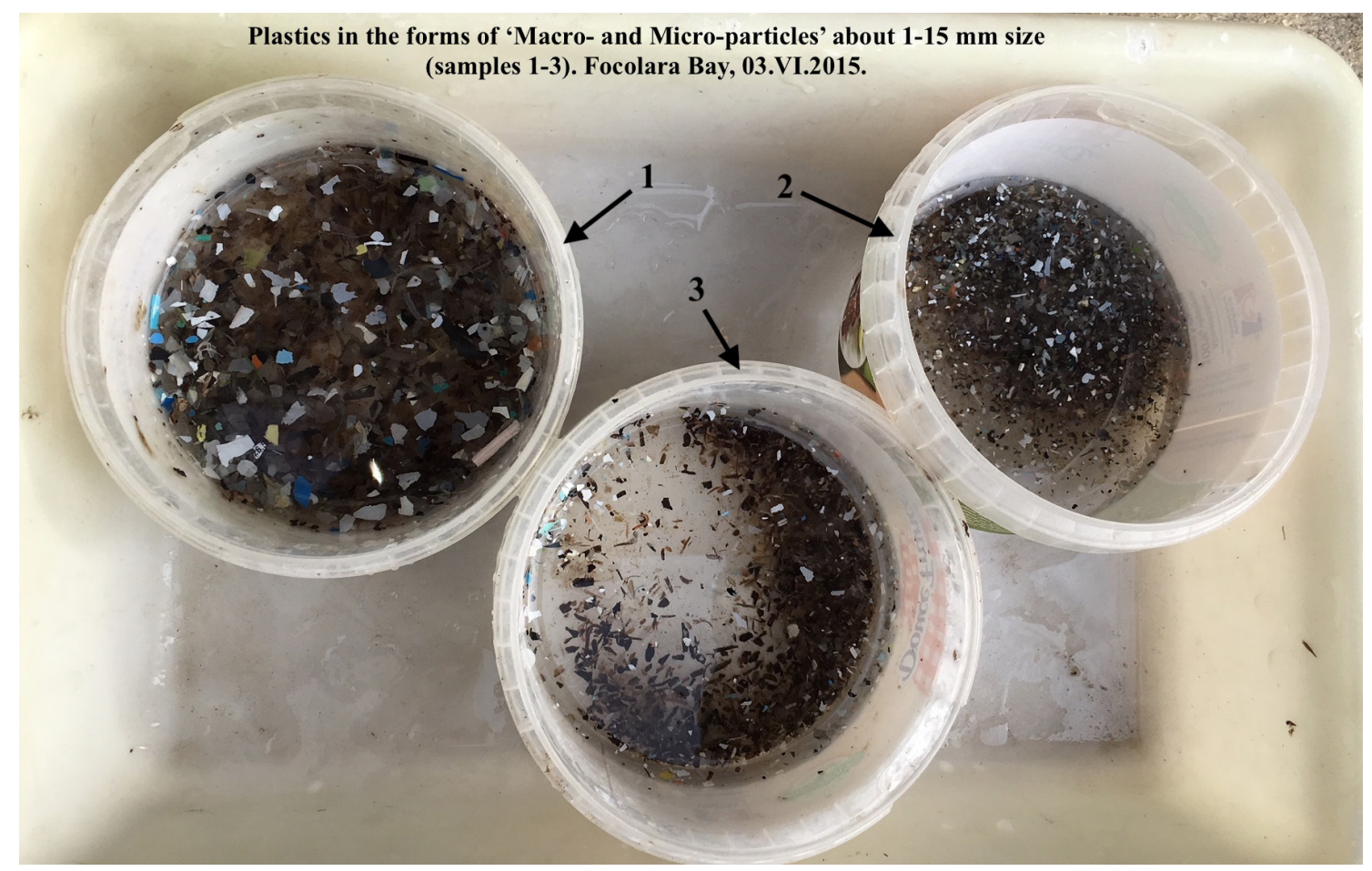

Figure 16. Plastics in the form of 'Macro- and Micro-particles' (1-5 to 10-15 mm size). Focolara Bay, Scandola Nature Reserve. Photo J. Moubayed-Breil.

suggestions, which greatly improved the manuscript. Special thanks are also due to Jade and MHélène Breil-Moubayed for their kind assistance in achieving the measurements of the leg ratios for the two new species.

\section{References}

Andersen, T. and Pinho, L.C. 2014. A new Thalassosmittia Strenzke \& Remmert, 1957 Out of the Sea: T. amazonica n. sp. from the Amazon Rainforest, Brazil (Diptera: Chironomidae, Orthocladiinae). - Chironomus Newsletter on Chironomidae Research 27: 25-30. https://doi. org/10.5324/cjcr.v0i27.1702

Andersen, T., Sæther, O.A., Cranston, P.S. and Epler, J.H. 2013. The larvae of Orthocladiinae (Diptera: Chironomidae) of the Holarctic Region - keys and diagnoses. - Insect Systematics \& Evolution, Supplement 66: 189-386.

Ashe, P. and O'Connor, J.P. 2012. A World Catalogue of Chironomidae (Diptera). Part 2. Orthocladiinae. Irish Biogeographical Society \& National Museum of Ireland, Dublin. 1-968. https://doi.org/10.5324/fn.v31i0.1366

Bequeart, M. and Goetghebuer, M. 1914. Deux Chironomides marins capturés sur le littoral belge (Clunio marinus Haliday et Camptocladius thalassophilus nov. spec.). - Annales de la
Société Entomologique de Belgique 57: 370377. https://doi.org/10.5962/bhl.part.4598

Blanfuné, A., Boudouresque, C.F., Verlaque, M. and Thibault, T. 2019. The ups and downs of a canopy-forming seaweed over a span of more than one century. - Scientific Reports 9, 5250: 1-9. https://doi.org/10.1038/s41598-01941676-2

Coffman, W.P., Cranston, P.S., Oliver, D.R. and Scether, O.A. 1986. The pupae of Orthocladiinae (Diptera: Chironomidae) of the Holarctic Region-keys and diagnoses. In Wiederholm, T. (ed.): Chironomidae of the Holarctic Region. Keys and diagnoses. Part 2 - Pupae. Entomologica Scandinavica, Supplement 28: 147-296.

Cranston, P.S., Oliver, D.R. and Scether, O.A. 1989. The adult males of Orthocladiinae (Diptera: Chironomidae) of the Holarctic Region-Keys and diagnoses. In: Wiederholm, T. (ed.): Chironomidae of the Holarctic region. Keys and diagnoses. Part 3-Adult males. - Entomologica Scandinavica, Supplement 34: 164-352.

Garrabou, J., Sala, E., Linares, C., Ledoux, J.B., Monterro-Serra, I., Dominici, J.M., Kipson, S., Teixido, N., Cebrian, E., Kersting, D.K. and Harmelin, J.G. 2017. Re-shifting the ecological baseline for the overexploited Mediterranean red coral. - Scientific Reports 7, 42404: 1-5. https://doi.org/10.1038/srep42404 
Heimbach, F. 1978. Sympatric species, Clunio marinus Hal. and C. balticus n. sp. (Dipt., Chironomidae), isolated by differences in diel emergence time. - Oecologia (Berl.) 32: 195202. https://doi.org/10.1007/BF00366071

Kaiser, T.S., Heckel, D.G. 2012. Genetic architecture of local adaptation in lunar and diurnal emergence times of the marine midge Clunio marinus (Chironomidae, Diptera). - PLoS ONE (2): e32092: 1-14. https://doi.org/10.1371/ journal.pone.0032092

Langton, P.H. 1991. A key to pupal exuviae of the West Palaearctic Chironomidae. Privately published. Huntingdon, England, 386 pp.

Langton, P.H. and Pinder, L.C.V. 2007. Keys to the adult males of Chironomidae of Britain and Ireland. Volume 1 (Pp: 1-239) and volume 2 (Pp. 1-68). Freshwater Biological Association, Scientific Publication, $\mathrm{n}^{\circ} 64$.

Linares, C., Bianchimani, O., Torrents, O., Marschal, C., Drap, P. and Garrabou, J. 2010. Marine Protected Areas and the conservation of long-lived marine invertebrates: the Mediterranean red coral. - Marine Ecology progress series 402: 69-79. https://doi.org/10.3354/ meps08436

Michailova, P. 1980a. Comparative external morphological and karyological characteristics of European species of genus Clunio Haliday, 1855 (Diptera, Chironomidae). In: Murray D.A. (ed.) Chironomidae. Pergamon Press, Oxford: 9-15. https://doi.org/10.1016/B978-008-025889-8.50007-6

Michailova, P. 1980b. A review of the European species of genus Clunio Haliday, 1855 (Diptera, Chironomidae). - Zoologischer Anzeiger 205(5/6): 417-432.

Morley, R.L. and Ring, R.A. 1972. The intertidal Chironomidae (Diptera) of British Columbia. II. Life history and population dynamics. - $\mathrm{Ca}$ nadian Entomologist 104: 1093-1098. https:// doi.org/10.4039/Ent1041093-7

Moubayed-Breil, J. and Ashe, P. 2012. An updated checklist of the Chironomidae of Corsica with an outline of their altitudinal and geographical distribution (Diptera). - Ephemera 13(1): 1339.

Moubayed-Breil, J. and Ashe, P. 2016. New records and additions to the database on the geographical distribution of some threatened chironomid species from continental France [Diptera, Chironomidae]. Ephemera 16(2): 121-136.
Moubayed-Breil, J., Verlaque, M., Dominici, J.M. and Bianconi, C.H. 2013. Estuarine zones of Corsica: Faunal, ecological and biogeographical data. - Travaux de l'Institut Scientifique, Rabat, Série Zoologie, 49: 43-58.

Neumann, D. 1976. Adaptation of chironomids to intertidal environments. - Annual Revue of Entomology 21: 387-414. https://doi.org/10.1146/ annurev.en.21.010176.002131

Neumann, D., Kaminsky, R. and Heimbach, F. 1997. Timing of eclosion in marine insects on Mediterranean shores-studies on Clunio mediterraneus, C. ponticus and Thalassomyia frauenfeldi (Diptera: Chironomidae). - Marine Biology 129(3): 513-521. https://doi.org/10.1007/ s002270050192

Sæther, O.A. 1969. Some Nearctic Podonominae, Diamesinae and Orthocladiinae (Diptera: Chironomidae). - Bulletin of the Fisheries Research Board of Canada 107: 1-154.

Sæther, O.A. 1977. Female genitalia in Chironomidae and other Nematocera: morphology, phylogenies, keys. - Bulletin of the Fisheries Research Board of Canada 197: 1-209.

Sæther, O.A. 1980. Glossary of chironomid morphology terminology (Diptera: Chironomidae). - Entomologica Scandinavica, Supplement 14: $1-51$.

Sæther, O.A. and Andersen, T. 2011. Chironomidae from Gough, Nightingale and Tristan da Cunha islands. - Zootaxa 2915: 1-19. https:// doi.org/10.11646/zootaxa.2915.1.1

Sæther, O.A., Ashe, P. and Murray, D.A. 2000. Family Chironomidae. In: Papp, L. and Darvas, B. (Eds.), Contributions to a Manual of Palaearctic Diptera (with special reference to flies of economic importance). Science Herald, Budapest, 4 (A6), 113-334.

Sæther, O.A. and Spies, M. 2013. Fauna Europaea: Chironomidae. In P. Beuk \& T. Pape (eds): Fauna Europaea: Diptera Nematocera. Fauna Europaea version 2.6. Internet database at http://www.faunaeur.org [accessed February 2015].

Sasa, M. and Suzuki, H. 1999a. Studies on the chironomid midges of Tsushima and Iki Islands, western Japan: Part 2. Species of Orthocladiinae and Tanypodinae collected on Tsushima. - Tropical Medicine 41(2): 75-132.

Sasa, M. and Suzuki, H. 1999b. Studies on the chironomid midges of Tsushima and Iki Islands, western Japan: Part 3. The chironomid species 
collected on Iki Island. - Tropical Medicine 41(3): 143-179.

Saunders, L.G. 1928. Some marine insects of the Pacicific Coast of Canada. - Annals of the Entomological Society of America 21(4): 521545. https://doi.org/10.1093/aesa/21.4.521

Spies, M., Andersen, T., Epler, J.H. and Watson, C.N. (Jr.). 2009. Chironomidae (Non-biting Midges). In: Brown, B.V., Borkent, A., Cumming, J.M., Wood, D.M., Woodley, N.E. and Zumbado, M.A. (Eds). Manual of Central American Diptera: Volume 1. NRC Research Press, Ottawa, Ontario, Canada, pp. 437-480.

Storå, R., 1936. Family Chironomidae. In Frey, R. (Ed.). Die Dipterenfauna der Kanarischen Inseln und ihre Probleme. - Commentationes Biologicae 6(1): 21-30.

Strenzke, K. 1960. Metamorphose und verwadtschaftsbeziehungen der gattung Clunio Hal. (Dipt.). Terrestrische Chironomidae XXIV. - Annales Zoologigi Societatis Zoologigae Botanicae Fennicae 'Vasamo', 22(4): $1-30$.

Strenzke, K. \& Remmert, H. 1957. Terrestrische Chironomiden. XVII. Thalassosmittia thalassophila (Bequ. u. Goetgh.). - Kieler Meeresforschungen 13(2): 263-273.

Sublette, J.E. 1967. Type specimens of Chironomidae (Diptera) in the Canadian National Collections, Ottawa. - Journal of the Kansas Entomological Society 40(3): 290-331.
Tasdemir, A. 2010. Clunio Haliday, 1855: A new chironomid genus for Turkey (Diptera, Chironomidae). - Journal of the Entomological Research Society 12(3): 39-43.

Tokunaga, M. 1936. Chironomidae from Japan (Diptera), VIII. Marine or seashore Spanioto$m a$, with descriptions of the immature forms of Spaniotoma nemalione sp. nov. and Tanytarsus boodleae Tokunaga. - Philippine Journal of Science 60(3): 303-321.

Verlaque, M. 2010. Field-methods to analyse the condition of Mediterranean Lithophyllum byssoides (Lamarck) Foslie rims. - Scientific Report, Port-Cros Natural Park 24: 185-196.

Wang, X. and Sæther, O.A. 1993. A new species of the 'marine' genus Thalassosmittia Strenzke \& Remmert from Xizang (Tibet), China (Diptera: Chironomidae). - Entomologica scandinavica 24(2): 211-214. https://doi. org/10.1163/187631293X00307

Yamamoto, M. 2004. A catalogue of Japanese Orthocladiinae (Diptera: Chironomidae). - Makunagi 21: 1-121.

Yamamoto, M., Suzuki M. and M. Yamamoto. 2019. Taxonomic notes on several Japanese chironomids (Diptera) described by Dr. M. Sasa and his co-authors. - Japanese Journal of Systematic Entomology 25(1): 63-72. 